\section{PRMT1 arginine methyltransferase accumulates in cytoplasmic bodies that respond to selective inhibition and DNA damage}

\author{
J. Suchánková, ${ }^{1}$ S. Legartová, ${ }^{1}$ \\ P. Sehnalová, ${ }^{1}$ S. Kozubek, ${ }^{1}$ S. Valente, ${ }^{2}$ \\ D. Labella, ${ }^{2}$ A. Mai, ${ }^{2}$ C. Eckerich, ${ }^{3}$ \\ F.O. Fackelmayer, ${ }^{3}$ D.V. Sorokin, ${ }^{4}$ \\ E. Bártová
}

${ }^{1}$ Institute of Biophysics, Academy of

Sciences of the Czech Republic, Brno,

Czech Republic

2Pasteur Institute - Fondazione Cenci

Bolognetti, Department of Chemistry and

Drug Technology, University of Rome La

Sapienza, Italy

${ }^{3}$ Institute of Molecular Biology and

Biotechnology, Department of Biomedical

Research (IMBB-FORTH), Foundation for

Research and Technology Hellas,

loannina, Greece

${ }^{4}$ Faculty of Informatics, Masaryk

University, Brno, Czech Republic

\section{Abstract}

Protein arginine methyltransferases (PRMTs) are responsible for symmetric and asymmetric methylation of arginine residues of nuclear and cytoplasmic proteins. In the nucleus, PRMTs belong to important chromatin modifying enzymes of immense functional significance that affect gene expression, splicing and DNA repair. By time-lapse microscopy we have studied the sub-cellular localization and kinetics of PRMT1 after inhibition of PRMT1 and after irradiation. Both transiently expressed and endogenous PRMT1 accumulated in cytoplasmic bodies that were located in the proximity of the cell nucleus. The shape and number of these bodies were stable in untreated cells. However, when cell nuclei were microirradiated by UV-A, the mobility of PRMT1 cytoplasmic bodies increased their, size was reduced, and they disappeared within approximately $20 \mathrm{~min}$. The same response occurred after $\gamma$-irradiation of the whole cell population, but with delayed kinetics. Treatment with PRMT1 inhibitors induced disintegration of these PRMT1 cytoplasmic bodies and prevented formation of 53BP1 nuclear bodies (NBs) that play a role during DNA damage repair. The formation of 53BP1 NBs was not influenced by PRMT1 overexpression. Taken together, we show that PRMT1 concentrates in cytoplasmic bodies, which respond to DNA injury in the cell nucleus, and to treatment with various PRMT1 inhibitors.

\section{Introduction}

Chromatin structure and function is controlled by many enzymes. ${ }^{1}$ Protein arginine methyltransferases (PRMTs) methylate histones and other regulatory and structural proteins, with particular activity in the nucleus. ${ }^{2,3}$ The PRMT family consists of 11 different methyltransferases (PRMT1-11) that control cellular processes such as transcription, RNA processing, nucleocytoplasmic shuttling of proteins, and DNA repair. ${ }^{4-7}$ Reflecting these diverse functions, several PRMTs are located in both the cytoplasm and the nucleus, but display cell-type-specific differences in the ratio of nuclear versus cytoplasmic PRMTs' distribution. ${ }^{8}$ Arginine methyltransferases in the nucleus act as epigenetic factors that induce transcriptional activation or silencing depending on the affected residue in core histones, and the symmetric or asymmetric nature of the methylation. ${ }^{9}$ For example, PRMT1 and PRMT5 can both dimethylate arginine 3 of histone $\mathrm{H} 4$ (H4R3). However, PRMT5 methylates H4R3 symmetrically, which leads to silencing, whereas PRMT1 methylates H4R3 asymmetrically, which is a chromatin mark that leads to activation. Histone deacetylation precedes PRMT5-mediated methylation of arginine residues on histones $\mathrm{H} 3$ and $\mathrm{H} 4 .^{10,11}$ This observation indicates that one histone mark can be replaced by another during both physiological and pathological processes in the nucleus. ${ }^{12,13}$

Arginine methylation by PRMTs also regulates the chromatin-related functions of DNA damage repair (DDR) pathways. For example, PRMT1 and PRMT6 are involved in nucleotide excision response via modification of DNA polymerase $\beta$ at R83 and R152,14 which increases DNA polymerase activity. However, when PRMT1 methylates R137 of DNA polymerase $\beta$, its association with proliferating cell nuclear antigen (PCNA; a marker for proliferation and DDR) is inhibited. ${ }^{14-17}$ PRMT1 also methylates MRE11, a member of the MRN complex. The MRN complex consists of MRE11, RAD50, and NBS1 and plays a fundamental role during homologous recombination (HR) in intra-S-phase checkpoint control, which is considered as one of the major DDR pathways. ${ }^{18-21}$ The absence of arginine methylation substantially reduces the exonuclease activity of MRE11.22 This result indicates that arginine methylation is involved in the repair of damaged DNA, along with other histone related DDR mechanisms appear. Examples
Correspondence: Eva Bártová, Institute of Biophysics, Academy of Sciences of the Czech Republic, v.v.i., Královopolská 135, CZ-612 65, Brno, Czech Republic. Tel. +420.5.41517141 - Fax: +420.5.41240498. E-mail: bartova@ibp.cz

Keywords: Epigenetics, PRMTs, epi-drugs, arginine methylation, DNA repair.

Conflict of interests: the authors declare no potential conflict of interests.

Funding: our work was supported by the following agencies: Grant Agency of Czech Republic (Grant N. P302/10/1022, P302/12/G157, and 13-07822S). EB, FOF, and AM are members of the EU-COST Action TD0905; EB is a principal investigator and coordinator of the EU Marie Curie Project PIRSES-GA-2010-269156-LCS. The postdoctoral fellowship of DVS was guaranteed by the Education for Competitiveness Operational Programme (ECOP), N. CZ.1.07/2.3.00/30.0030.

Contributions: JS, cell culture cultivation, treatments, plasmid DNA isolation, cell transfection, live cell studies after UV-A irradiation, immunofluorescence studies; SL and PS, immunofluorescence and intermediated irradiation of the cells with $\gamma$-rays; SK, GACR projects P302/10/1022 and P302/12/G157 coordination; CE, provided YFPPRMT1 plasmid DNA; FOF, manuscript contribution to composition and critical reading, provided YFP-PRMT1 plasmid DNA; AM, SV, DL, provided MC 1981 and MC 2089 inhibitors; DVS, single particle tracking analysis; EB, experiments design, experimental strategy coordination.

Received for publication: 25 February 2014. Accepted for publication: 17 March 2014.

This work is licensed under a Creative Commons Attribution NonCommercial 3.0 License (CC BYNC 3.0).

@CCopyright J. Suchánková et al., 2014 Licensee PAGEPress, Italy

European Journal of Histochemistry 2014; 58:2389 doi:10.4081/ejh.2014.2389

are: phosphorylation of $\mathrm{H} 2 \mathrm{AX},{ }^{23}$ specific acetylation states of histones connected with DNA lesions, ${ }^{24-26}$ ubiquitination/sumoylation, ${ }^{27}$ or poly(ADP-ribosyl) ation (PARylation)..$^{28,29}$ Arginine methylation appears to be critically involved in maintaining genome stability. Thus, the study of PRMT inhibitors and other epidrugs may lead to new approaches of how to modulate DNA repair for medical purposes. ${ }^{30-32}$ For example, the main goal of epidrugs is to reverse pathological states of chromatin to relatively normal conditions. To address this, we studied the kinetics of PRMT1 after cell treatment with the PRMT1-selective inhibitors MC 1981 and MC 2089, which could be considered as potential anti-cancer drugs. In complementary assays, we investigated the subcellular 
localization of PRMT1 in live cells treated with selected epi-drugs, and after ultraviolet (UVA)-microirradiation and $\gamma$-irradiation. The results significantly expand our knowledge of how cells respond to targeted intervention to the epigenome, and how PRMT1 contributes to the DNA damage response.

\section{Materials and Methods}

\section{Cell culture}

For experiments we used following cell lines: immortalized mouse embryonic fibroblasts (iMEFs), human U20S osteosarcoma cells [originally from American Type Culture Collection, designated as U-2 OS (ATCC ${ }^{\circledR}$ HTB$\left.96^{\mathrm{TM}}\right)$ ], and HeLa cervical carcinoma cells (ATCC $^{\circledR}$ CCL-2 ${ }^{\mathrm{TM}}$ ). Immortalized MEFs were cultivated in Dulbecco's modified Eagle's medium supplemented with $10 \%$ fetal calf serum. Additionally we used D3 mouse embryonic stem cells (mESCs, line ES-D3; purchased from ATCC $^{\circledR}$ CRL1934 $^{\mathrm{TM}}$ ) that were maintained in complete mESC medium as described by Šustáčková et al. ${ }^{33}$ Human ESC line ${ }^{34}$ (hESCs) was cultivated under feeder-free conditions using an hESC-specific matrix (Matrigel) and mTeSR ${ }^{\mathrm{TM}} 1$ complete medium with specific growth factors. Human ESCs were purchased and maintained according to the Czech national law 227/2006, and Ethics Committee agreement No.: 616/2012-31. All cell lines used were maintained at $37^{\circ} \mathrm{C}$ in a humidified atmosphere containing $5 \% \mathrm{CO}_{2}$.

\section{Cell transfection by plasmids encoding YFP-PRMT1 and GFP-BMI1}

YFP-PRMT1 was generated by subcloning the coding region of PRMT isoform $1^{35}$ into the NheI and HindIII sites of the pEYFP-N1 vector (Clontech, Heidelberg, Germany). The plasmid was transformed into $E$. coli $\mathrm{DH} 5 \alpha$, and then isolated using the Qiagen Large-Construct kit (\#12462, Qiagen, Bio-Consult, Prague, Czech Republic). Eukaryotic cells were transfected with plasmid DNA using the METAFECTENE ${ }^{\mathrm{TM}-}$ PRO system (Biontex Laboratories $\mathrm{GmbH}$, Planegg, Germany) (Supplementary figure 1A). U20S cells stably expressing GFP-BMI1, which was a positive control that shows protein accumulation in response to locally induced double-strand breaks (Supplementary figure 1B), were a generous gift from Dr. Dušan Cmarko (First Faculty of Medicine, Charles University, Prague, Czech Republic). These cells originated from the laboratory of Dr. Maarten van Lohuizen (Division of Molecular Genetics, Netherlands Cancer Institute, Amsterdam, the Netherlands).

\section{Fluorescence recovery after photo- bleaching}

The fluorescence recovery after photobleaching (FRAP) experiments were performed using the argon laser (488 nm) of a Leica TSC SP-5 X confocal microscope (Leica Microsystems, Mannheim, Germany). The objective magnification was $64 \times$ and the numerical aperture was 1.4. Live cells were
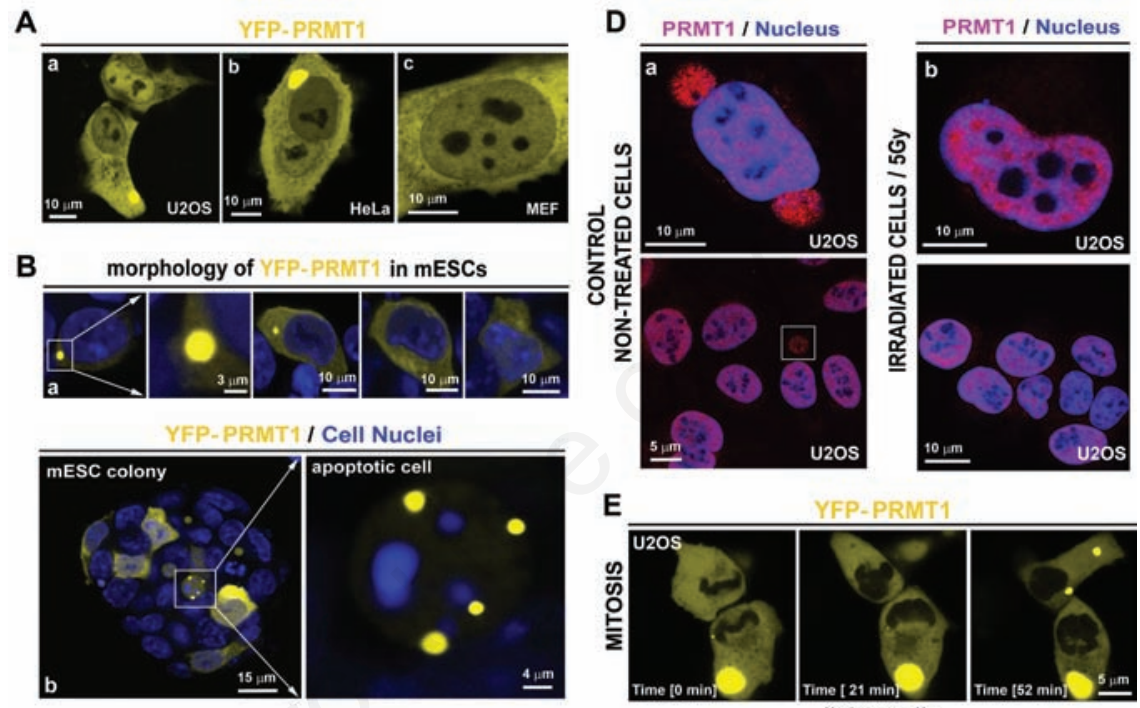

E
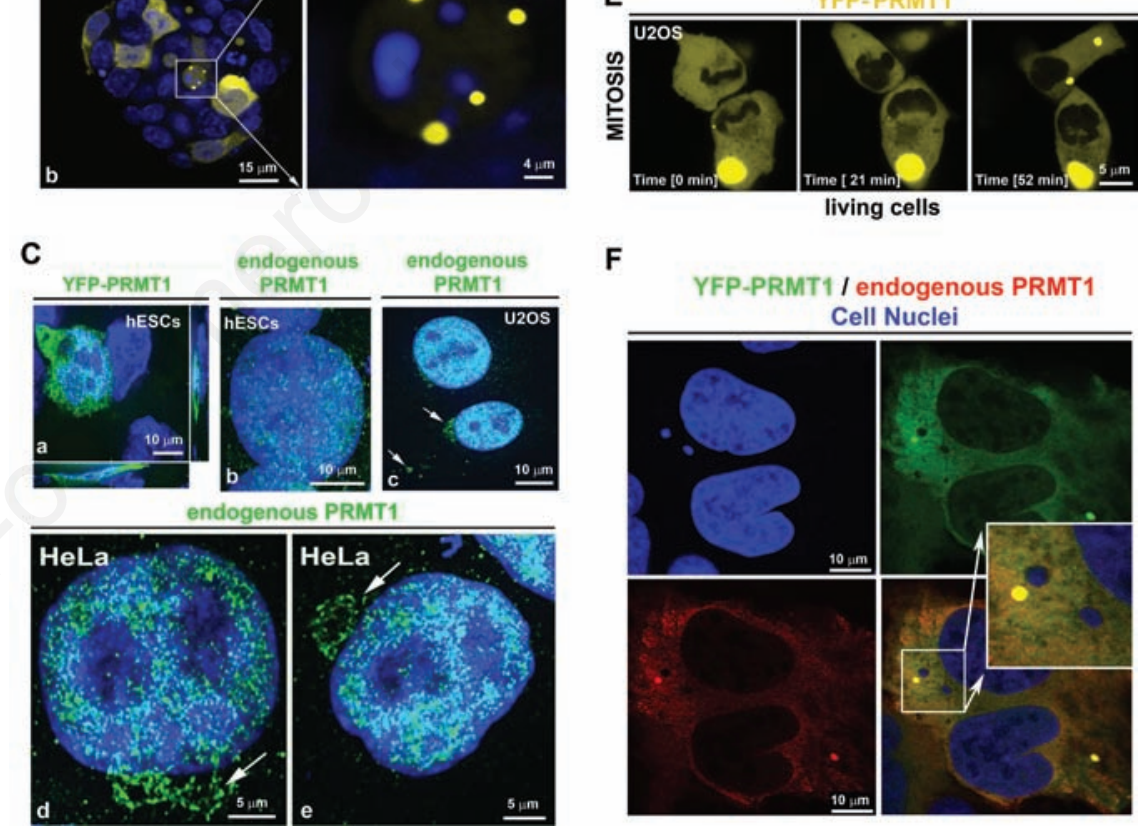

$\mathbf{F}$

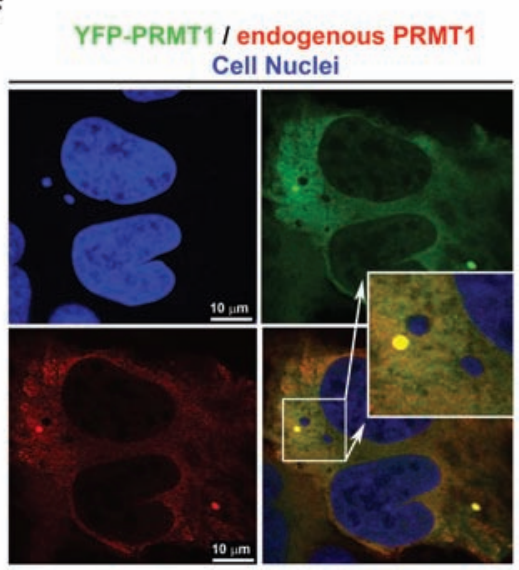

Figure 1. Morphology of PRMT1 in different cell types. A) PRMT1 in PRMT1 cytoplasmic bodies is shown in cells transiently expressing YFP-PRMT1; nucleocytoplasmic distribution of PRMT1 is shown in (a) U2OS cells, (b) HeLa cells (c) mouse embryonic fibroblasts (iMEFs). B) PRMT1 in (a) individual mouse embryonic stem cells (mESCs), and (b) in a colony of mESCs and selected apoptotic cell (right panel; magnified cell); apoptotic cells contained apoptotic bodies that were positive for YFP-PRMT1, but these bodies were absent from DAPI-stained chromatin (see magnification in panel $\mathrm{Bb}$ ). C) YFP-PRMT1 pattern in (a) human embryonic stem cells (3D projections from confocal microscopy); panels show endogenous PRMT1 in human embryonic stem cells (b), endogenous PRMT1 in U2OS cells (c), and endogenous PRMT1 in HeLa cells (d,e); arrows show the morphology of endogenous PRMT1 cytoplasmic aggregates; images in panel $\mathrm{C}$ were acquired by Nipkow disc-based confocal microscopy. D) Comparison of morphology of PRMT1 cytoplasmic bodies (red) in (a) control non-treated cells and (b) $\gamma$-irradiated U2OS cell nuclei (blue). E) PRMT1 cytoplasmic bodies did not disappear during mitosis. F) PRMT1 cytoplasmic bodies (red and green) did not co-localize with DAPI-positive micronuclei (blue). 
of PRMT1 cytoplasmic bodies. Images of the live cells were captured every $10 \mathrm{~s}$ at a resolution of $1024 \times 1024$ pixels and a speed of 400 $\mathrm{Hz}$. The bidirectional scanning mode was used for time-lapse microscopy, and LEICA LAS AF software was used for analysis of fluorescence intensity. Statistical analysis (Student's $t$-test) was performed with SigmaPlot software, version 8.0.

\section{Immunofluorescence}

Cells were fixed with $4 \%$ formaldehyde for 10 min at room temperature (RT), permeabilized with $0.2 \%$ Triton X-100 for 8 min, incubated in $0.1 \%$ saponin (Sigma-Adrich, Prague, Czech Republic) for 12 min, and washed twice in phosphate-buffered saline (PBS) for $15 \mathrm{~min}$. Slides with fixed cells were incubated in $1 \%$ bovine serum albumin in PBS for $1 \mathrm{~h}$, washed in PBS for $15 \mathrm{~min}$, and incubated with antibodies against 53BP1 (Abcam, Cambridge, UK, \#ab21083), anti-phosphoH2AX (Abcam, \#ab22551), anti- $\alpha$-tubulin ([DM1A] antibody, Abcam, \#ab80779), anti-26S proteasome (Abcam, \#ab58115) or anti-PRMT1 (Abcam, \#ab73246). The cells were incubated overnight at $4^{\circ} \mathrm{C}$ with primary antibodies and then incubated with secondary antibodies. Immunocytochemistry and image acquisition by Nipkow disc-based confocal microscopy was performed according to Strašák et al. ${ }^{37} \mathrm{~F}$-actin was visualized by phalloidin (Alexa Fluor ${ }^{\circledR} 594$ Phalloidin, Invitrogen, Prague, Czech Republic, \#A12381 or Phalloidin, Fluorescein Isothiocyanate Labeled, Sigma-Aldrich, \#P5282) according to Bártová et al. ${ }^{25}$ Change in mitochondrial morphology we assayed by staining with MitoTracker ${ }^{\circledR}$ Deep Red FM (Invitrogen, \#M22426). ${ }^{25}$

\section{Cell treatment with PRMT1}

\section{inhibitors and western blots}

Cells transiently or stably expressing YFPPRMT1 were cultivated at $37^{\circ} \mathrm{C}$ in a humidified atmosphere containing $5 \% \mathrm{CO}_{2}$. U2OS cells at $70 \%$ confluence transiently expressing YFP-PRMT1 were treated with $100 \mu \mathrm{M}$ MC 1981 or $100 \mu \mathrm{M}$ MC 2089 (PRMT1 inhibitors, see chemical formulas in Supplementary Figure 2A) for 4, 24, and $48 \mathrm{~h}$. As a solvent we used $0.05 \%$ dimethyl sufoxide (DMS0); similar concentration of DMSO was used for the treatment of control cells. The term control non-treated cells was used for the cells treated by $0.05 \%$ DMSO, but no treatment by inhibitors was used. The effects of the inhibitors were assessed by western blotting. Western blots were performed according to Strašák et al. ${ }^{37}$ and we used following antibodes: anti- $\alpha$-tubulin (Thermo Fisher Scientific, Waltham, MA, USA \#LF-PA0146) and anti-PRMT1 (Abcam, \#ab73246). Cell numbers were determined by cell counting in an automated cell counter

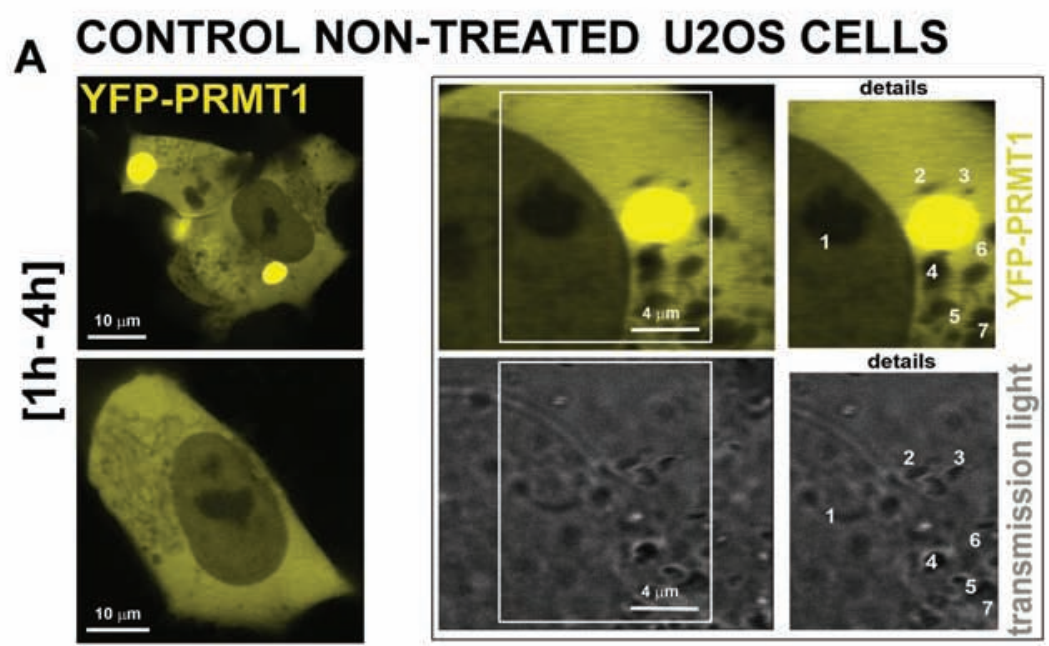

B PRMT1 INHIBITOR MC 1981
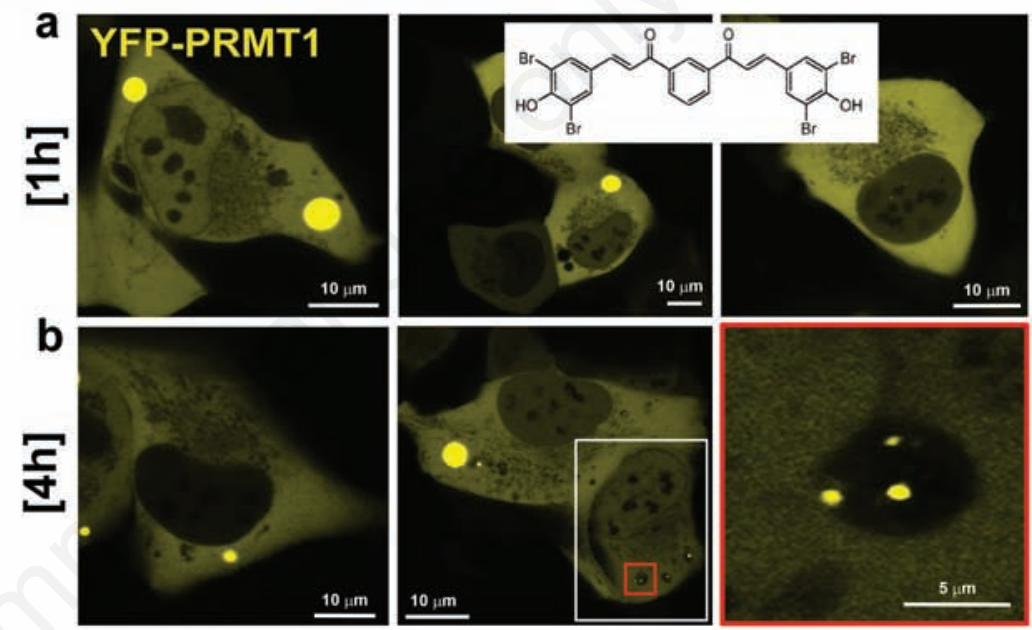

C PRMT1 INHIBITOR MC 2089
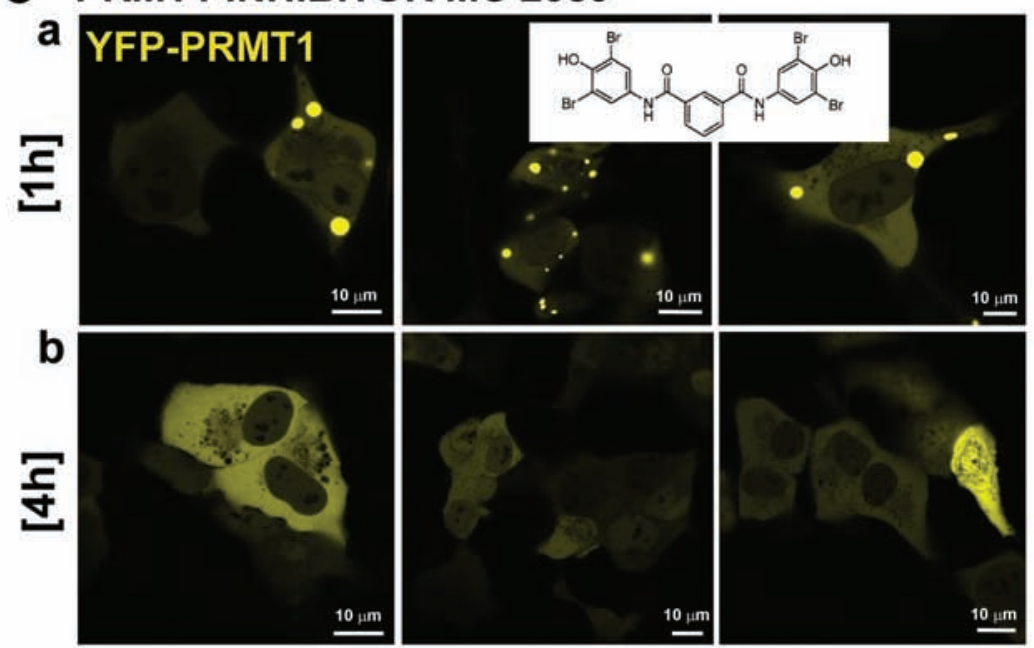

Figure 2. Morphology of PRMT1 cytoplasmic bodies in U2OS cells treated with PRMT1 inhibitors MC 1981 and MC 2089. The morphology of PRMT1 cytoplasmic bodies in transfected cells expressing YFP-PRMT1 was observed. A) Untreated control. B) Treatment with MC 1981 for $1 \mathrm{~h}$ and $4 \mathrm{~h}$. C) Treatment with MC 2089 inhibitor for 1 $h$ and $4 \mathrm{~h}$. 
TC10 (Bio-Rad, Hercules, CA, USA) before and after exposure to the epi-drugs. Cells were harvested after seeding (time 0 ) and after the treatment at intervals 4,24 and $48 \mathrm{~h}$ [Supplementary Figure 2B shows cell viability (a) and changes in cell numbers (b) after the treatment]. Cells were treated $24 \mathrm{~h}$ after the seeding.

Additional experiments also involved cell treatments with the proteasome inhibitor MG 132. The treatment was by $5 \mu \mathrm{M}$ MG 132 inhibitor for $16 \mathrm{~h}$. Cell numbers were calculated and western blots on PRMT1 levels were performed. Effects of PRMT1-related compounds were published by Mai et al. ${ }^{38}$ These authors showed that the use of these compounds, inhibits PRMT1, and also PRMT4, SET7, p300 and SIRT1/2 (MC1981 only). However, it highly depends on concentration. Here, we optimized concentration of these compounds in order to minimize induction of cell death (see cell viability in Supplementary Figure $2 \mathrm{Ba}$ ). Additional western blots showed reduced PRMT1 levels after the treatment by inhibitors. Western blot data were normalized to total protein levels and to $\alpha$-tubulin.

\section{Induction of local DNA lesions in living cells and $\gamma$-irradiation}

Individual cells were locally microirradiated using a UV-A laser. ${ }^{25,26}$ Entire cell populations were also irradiated with 5 Gy $\gamma$-rays ${ }^{60} \mathrm{Co}$; Chisostat, Chirana, Czech Republic). For localized UV-A microirradiation, cells were sensitized with $10 \mu \mathrm{M}$ BrdU for 16 to $18 \mathrm{~h}$ before the experiment. ${ }^{25,26}$ For DNA damage experiments and time-lapse microscopy, cells were placed in the cultivation hood (EMBL Heidelberg, Germany) and maintained at $37^{\circ} \mathrm{C}$ and $5 \% \mathrm{CO}_{2}$. BrdU-sensitized cells were irradiated with a UVA laser (wavelength $355 \mathrm{~nm}$ ) (Supplementary figure 1B a-c) connected to the Leica TSC SP-5X microscope. Defined regions of interest [(ROI), Supplementary Figure 1B d-f] were irradiated with $80 \%$ laser output that was not reduced by an acousto-optic tunable filter. We used the following settings: $512 \times 512$ pixel resolution, 400 $\mathrm{Hz}$, bidirectional mode, 64 lines, zoom $>5 \times$. For some experiments, microirradiated cells were fixed in $4 \%$ formaldehyde and markers of UV-A damaged chromatin, including $\gamma \mathrm{H} 2 \mathrm{AX}$ or 53BP1, were detected using rabbit polyclonal antibodies against $\gamma \mathrm{H} 2 \mathrm{AX}$ (phospho S139; Abcam, \#ab22551) or against 53BP1 (Abcam, \#ab21083) as described previously. 25,26

\section{Results}

\section{Localization of YFP-PRMT1 in various cell types}

The nucleocytoplasmic distribution of
PRMTs in various cell types was published by Herrmann et al. ${ }^{35}$ We confirmed the nucleocytoplasmic distribution of PRMT1 in U2OS and HeLa cells (Figure 1A a,b; Supplementary Figure 1A). Mouse embryonic fibroblasts displayed a high level of YFP-PRMT1 in the cytoplasm (compare Supplementary Figure 1A d with Figure 1A a-c), and these cells had also YFP-PRMT1 homogenously dispersed within the cell nucleus (Figure 1A c). In mESCs growing in well-defined colonies, transfected cells showed a high level of PRMT1 in both the cytoplasm and nuclei stained by DAPI (Figure 1B a,b). In hESCs, YFP-PRMT1 (variant v1) was localized in both the nucleus and the cytoplasm (Figure 1C a), whereas endogenous PRMT1 (a mixture of at least seven splicing isoforms; see Goulet et al. ${ }^{39}$ ) was localized pre-

\section{A CONTROL NON-TREATED U2OS CELLS [48h]}

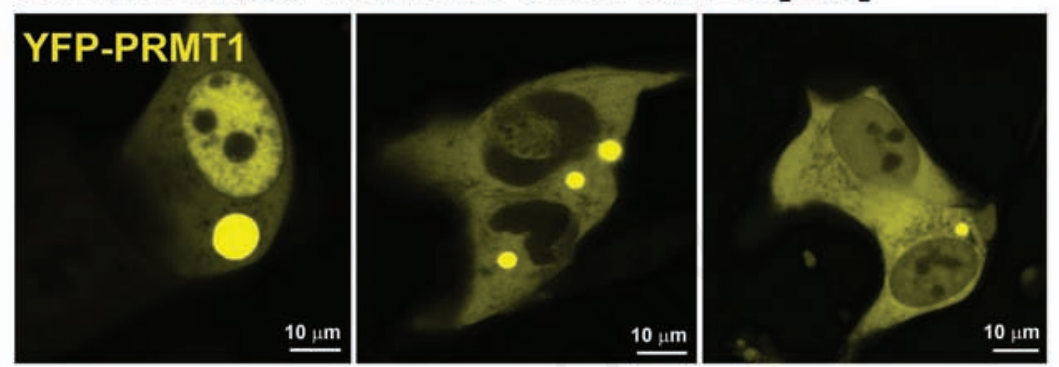

B PRMT1 INHIBITOR MC 1981 [48h]

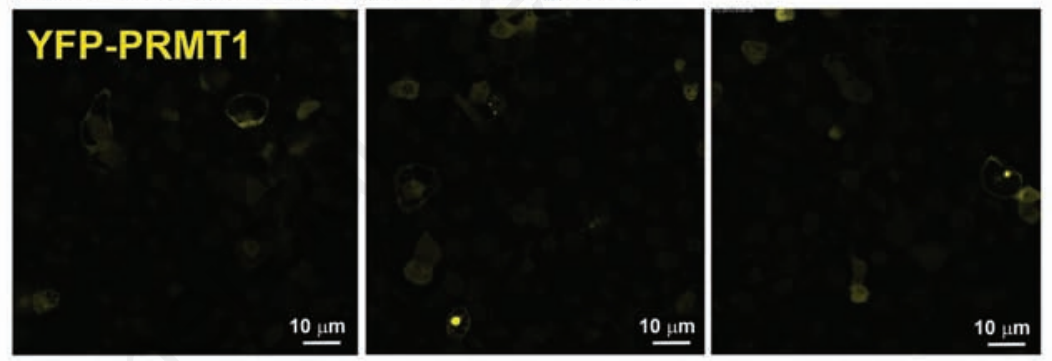

C

PRMT1 INHIBITOR MC 2089 [48h]
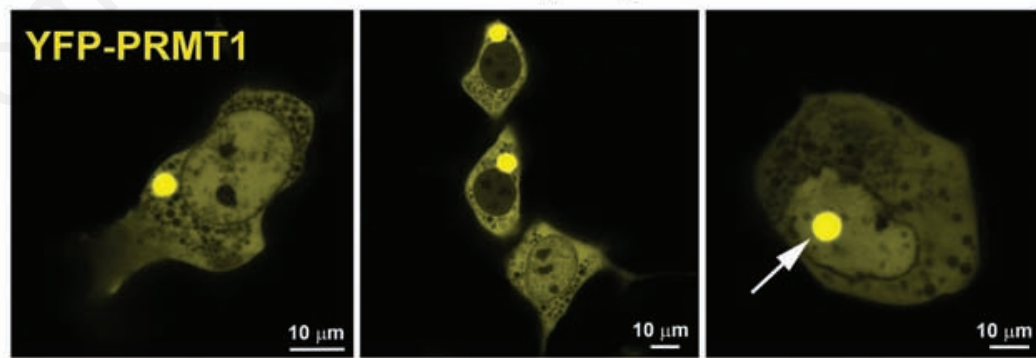

D

PRMT1 INHIBITOR MC 2089 [48h] - wash [1-4h]
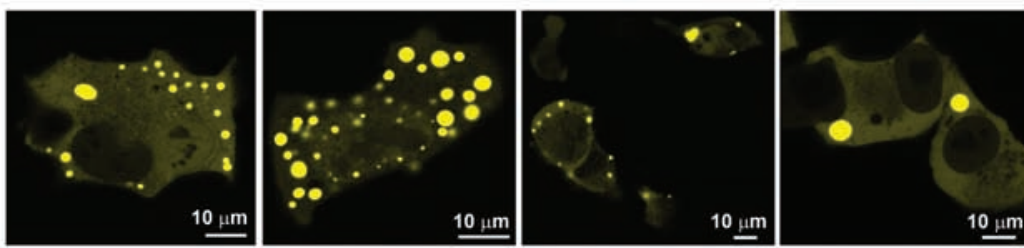

Figure 3. PRMT1 levels and PRMT1 cytoplasmic bodies' morphology at $48 \mathrm{~h}$ after treatment with PRMT1 inhibitors MC 1981 and MC 2089. The morphology of PRMT1 cytoplasmic bodies in transfected cells expressing YFP-PRMT1 was observed. A) PRMT1 levels and PRMT1 cytoplasmic bodies morphology were not affected in untreated control U2OS cells during $48 \mathrm{~h}$. B) MC 1981 strongly reduced the PRMT1 level after $48 \mathrm{~h}$. C) MC 2089 did not significantly affect PRMT1 levels or PRMT1 cytoplasmic bodies morphology at $48 \mathrm{~h}$; this indicates that cells recovered from the inhibitory effects observed after $4 \mathrm{~h}$ treatment with MC 2089 (see Figure 2C b). D) Cells were treated with MC 2089 for $48 \mathrm{~h}$, washed with PBS, and re-treated with MC 2089 for 1 to $4 \mathrm{~h}$. 
dominantly in the nucleus (Figure $1 \mathrm{C}$ b). In all cell types, we observed a strong accumulation of YFP-PRMT1 into round or oval structures in the cytoplasm, often in proximity to the nucleus (Figure 1A b). We designated these structures as PRMT1 cytoplasmic bodies. YFPPRMT1 cytoplasmic bodies achieved diameters up to $4.3 \mu \mathrm{m}$ (mean $3.7 \pm 0.2 \mu \mathrm{m}$ ) in non-treated control cells (Supplementary Figure 2C a). Similar structures we observed when analyzing endogenous PRMT1 (Figure 1C c-e). These cytoplasmic bodies were detected by immunofluorescence in non-transfected control cells (Figure 1C c-e, arrows).

Interestingly, endogenous PRMT1-positive cytoplasmic bodies disappeared after $\gamma$-irradiation of whole cell population (compare Figure 1D a as control and 1D b showing $\gamma$-irradiated cells). Although endogenous PRMT1-like structures were not as compact as exogenous PRMT1 cytoplasmic bodies, formed by transiently expressed YFP-PRMT1v1 (Figure 1A a,b), we believe that they represent the endogenous form of cytoplasmic PRMT1 accumulation (Figure 1C c-e). This result suggests that formation of the PRMT1 cytoplasmic bodies is not only due to transient expression of YFP-PRMT1, because both endogenous and exogenous PRMT1 cytoplasmic bodies were relatively stable in untreated control cells (Figure 1A, 1D a and Figure 2A) and did not disappear during mitosis (Figure 1E). Here, we additionally observed that PRMT1 of cytoplasmic bodies are not a component DAPIpositive micronuclei that we found in tumor U20S cells (Figure 1F, frame) and after $\gamma$-irradiation (not shown). We also observed that spontaneously occurring apoptotic cells were characterized by specific morphology, including the appearance of apoptotic bodies with strong PRMT1 fluorescence (Figure 1B b, frame). PRMT1-positive apoptotic bodies were absent in DAPI-stained chromatin (magnification in Figure 1B b). However, the appearance of PRMT1 cytoplasmic bodies in intact cells was not a consequence of pre-apoptotic events, which was confirmed by tracking the time span of cell survival without signs of apoptosis (Figures 2, 3 and 4, panels A) and by tracking of live cells passing through mitosis (Figure 1E).

\section{PRMT1 morphology after cell treat-} ment with selective PRMT1

\section{inhibitors}

In living U20S cells, YFP-PRMT1 accumulated in both the nucleus and the cytoplasm, with higher levels in the cytoplasm (Figure 2A). In untreated control cells, one large PRMT1 cytoplasmic body was observed in 30 to $40 \%$ of the cells, but in transmission light no vacuole was observed at the location of the big PRMT1 cytoplasmic bodies (Figure 2A, images from trans-

\section{A CONTROL NON-TREATED U2OS CELLS}

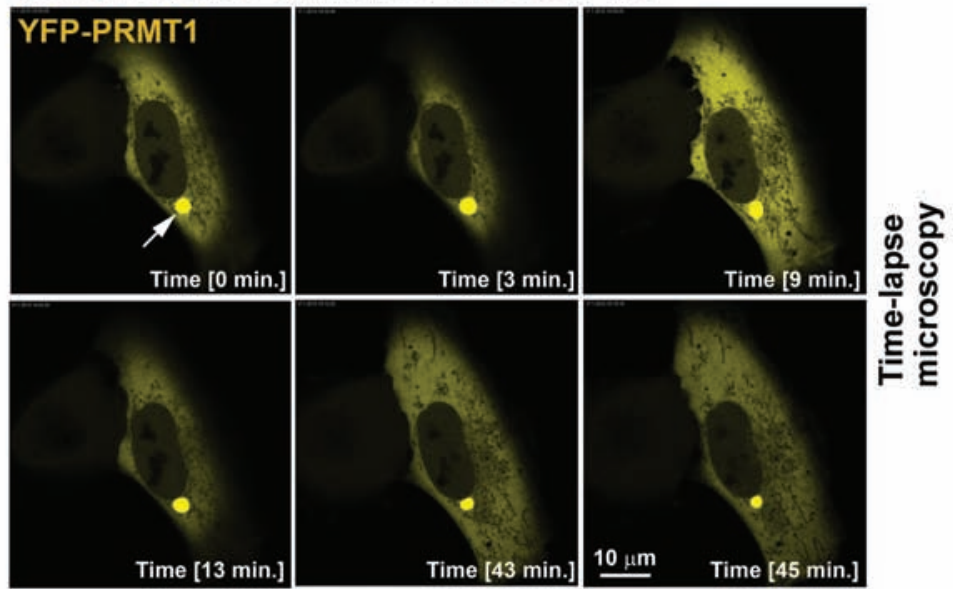

B PRMT1 INHIBITOR MC $1981[4 \mathrm{~h}]$
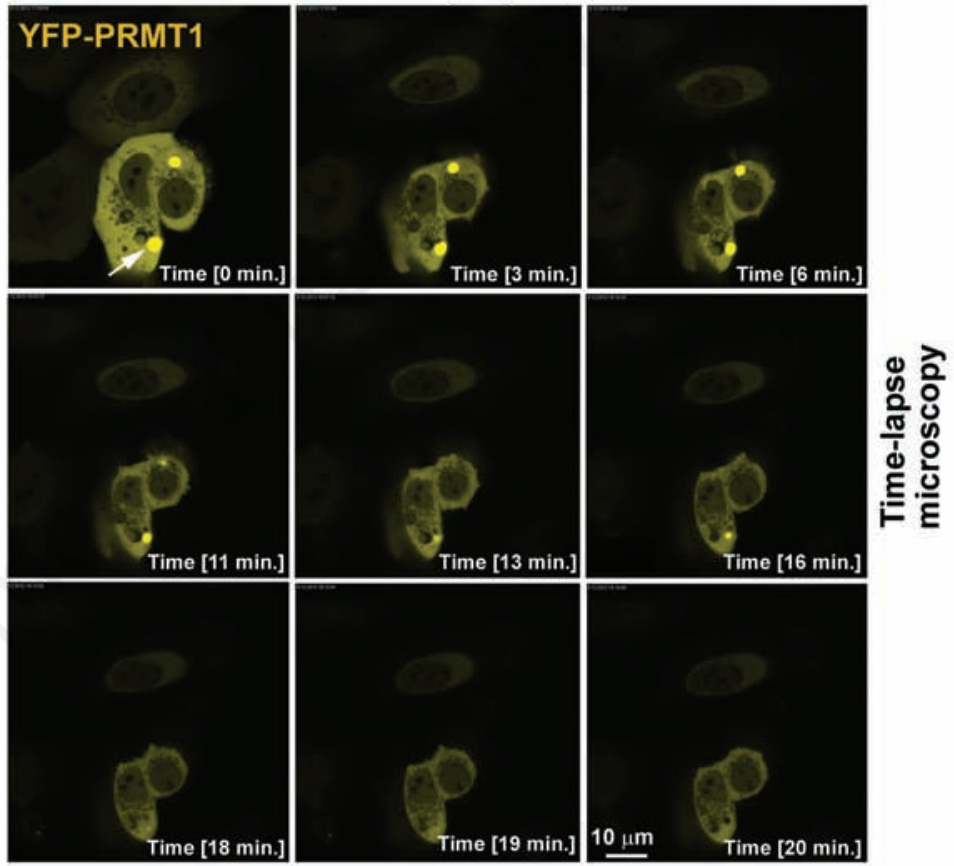

\section{PRMT1 INHIBITOR MC 2089 [48h]}
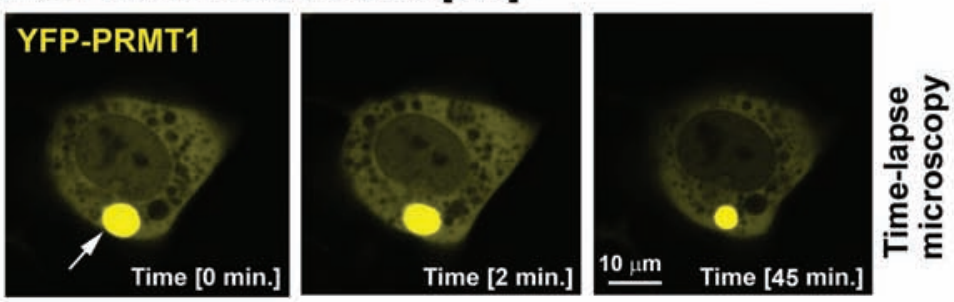

Figure 4. Time-lapse confocal microscopy of PRMT1 cytoplasmic bodies. Individual time sequences are shown for PRMT1 cytoplasmic bodies (white arrows) in control, MC 1981 or MC 2089 treated cells. A) PRMT1 cytoplasmic bodies are mobile with stable morphology during 45 to $50 \mathrm{~min}$ observation in control non-treated U2OS cells. B) Treatment with MC 1981 for $4 \mathrm{~h}$ caused that PRMT1 cytoplasmic bodies disappear during 18 to $20 \mathrm{~min}$, as observed with confocal microscope. C) U2OS cells treated with MC 2089 for 48 h recovered normal PRMT1 cytoplasmic bodies morphology. Cells recovered from the inhibitory effects $48 \mathrm{~h}$ after the treatment, but PRMT1 inhibition was observed after $4 \mathrm{~h}$ treatment with MC 2089 (see Figure 2C b). After $48 \mathrm{~h}$ of MC 2089 treatment, PRMT1 cytoplasmic bodies did not disappear during 30-45 min observation with confocal microscopy, which was comparable with the observations of untreated control U2OS cells. 
mission light). Treatment of cells with the PRMT1 inhibitor MC 1981 had no significant effect on the nucleocytoplasmic distribution of PRMT1, which was similar to that in untreated control cells for up to $1 \mathrm{~h}$ after the start of treatment (Figure 2B). However, after $4 \mathrm{~h}$ of treatment, approximately $30 \%$ of transfected cells were characterized by an absence of PRMT1 in the cell nucleus, and the number of smaller PRMT1 cytoplasmic bodies in the cytoplasm often increased to 2 to 3 per cell (Figure $2 \mathrm{~B} \mathrm{~b}$ ). At $1 \mathrm{~h}$ after the start of MC 1981 treatment, the average diameter of PRMT1 cytoplasmic bodies was $4.3 \pm 0.7 \mu \mathrm{m}$. At $4 \mathrm{~h}$ after treatment, the average diameter was $3.4 \pm 0.4 \mu \mathrm{m}$. In some cells, we observed vacuole-like structures that contained several small PRMT1 cytoplasmic bodies of average diameter $0.77 \pm 0.08 \mu \mathrm{m}$ (Figure 2B b, magnification in red frame). Treatment with the second, structurally related PRMT1 inhibitor MC 2089 increased the number of PRMT1 cytoplasmic bodies up to 3 to 4 after $1 \mathrm{~h}$ of treatment, but significantly reduced their size from a mean diameter of $3.7 \pm 0.2 \mu \mathrm{m}$ in untreated cells to $1.85 \pm 0.11 \mu \mathrm{m}$ in treated cells (compare Figures $2 \mathrm{~A}$ and $2 \mathrm{C}$ a, Supplementary Figure $2 \mathrm{C}$ a). By $4 \mathrm{~h}$ after the start of MC 2089 treatment, majority of PRMT1 cytoplasmic bodies disappeared and were no longer detected in the cytoplasm (Figure $2 \mathrm{C} \mathrm{b}$; Supplementary Figure 2C b).

During $48 \mathrm{~h}$ observation of untreated U20S cells, there was no change in the appearance of PRMT1 cytoplasmic bodies (Figure 3A). U20S cells treated with MC 1981 completely lost YFP-PRMT1 fluorescence after $48 \mathrm{~h}$ (Figure 3B). By contrast, cells treated with MC 2089 for $48 \mathrm{~h}$ recovered from the inhibitory effect with no loss in YFP-PRMT1 fluorescence, and again displayed one large PRMT1 cytoplasmic bodies per cell (Figure 3C). We observed PRMT1 cytoplasmic bodies not only in the cytoplasm, but also in the nucleus in some cells ( $0.5 \%$ of transfected cells) (Figure $3 \mathrm{C}$, right panel with arrow), a phenotype that was rarely observed in untreated cells. When the cells were washed, and MC 2089 was added at $48 \mathrm{~h}$ from the first treatment, PRMT1 cytoplasmic bodies were disassembled again within 1 to 4 h. Approximately $50 \%$ of the cells lacked PRMT1 cytoplasmic bodies by $4 \mathrm{~h}$ after the start of the second treatment, and the remaining cells were characterized by several PRMT1 cytoplasmic bodies in the cytoplasm as shown in Figure 3D.

\section{Dynamics of PRMT1 cytoplasmic bodies in control and PRMT1- inhibited cells}

We performed time-lapse confocal microscopy to investigate the localized movement of PRMT1 cytoplasmic bodies in live cells. In untreated control transfected cells,
PRMT1 cytoplasmic bodies were observed in 30 to $40 \%$ of cells (Supplementary Figure $2 \mathrm{C} \mathrm{b}$ ), and were stable and continuously visible during 45 to $50 \mathrm{~min}$ observation (Figure 4A). In cells that were pretreated with the inhibitor MC 1981 for 4 h, PRMT1 cytoplasmic bodies disappeared during 18 to 20 min of observation with the confocal microscope (Figure 4B). In cells that were pretreated with the inhibitor MC 2089 for 4 h, PRMT1 cytoplasmic bodies appeared only occasionally in 2 to $5 \%$ of transfected cells (Supplementary Figure 2C b), but had completely disappeared in the majority of cells (Figure 2C b). After $48 \mathrm{~h}$ of treatment with MC 2089, cells recovered their original PRMT1 cytoplasmic body morphologies and were indistinguishable from control cells. The regenerated PRMT1 cytoplasmic bodies were mobile, but did not disappear during 30 to 45 min of observation (Figure 4C, Supplementary Figure $2 \mathrm{C} \mathrm{b}$ ), which suggests that they behave like PRMT1 cytoplasmic bodies in untreated control cells. After $48 \mathrm{~h}$ of treatment with MC 2089, cells were washed by PBS and MC 2089 was added repeatedly to a cell culture (Figure 3D), time-lapse confocal microscopy showed that $5 \%$ of transfected cells contained PRMT1 cytoplasmic bodies. When the remaining MC 2089 treated cells with PRMT1 cytoplasmic bodies (2 to $5 \%$ ) were monitored, complete disassembly of PRMT1 cytoplasmic bodies occurred during 25 to $40 \mathrm{~min}$ (data not shown), depending on the size of multiple PRMT1 cytoplasmic bodies.

We have additionally analyzed localized movement of PRMT1 nuclear bodies by single particle tracking analysis. ${ }^{40}$ We observed that in comparison with non-treated control cells, localized movement of PRMT1 bodies was changed especially after MC 1981 treatment and in the cells irradiated by 5 Gy of $\gamma$-rays (Figure $5 \mathrm{~A}, \mathrm{~B}$ ).

To further characterize PRMT1 cytoplasmic bodies, we investigated whether PRMT1 was degraded by the ubiquitin-proteasome system. ${ }^{41}$ Moreover ubiquitin also contains arginine residues that can be potentially methylated. ${ }^{42}$ Alternatively, PRMT1 cytoplasmic bodies
A
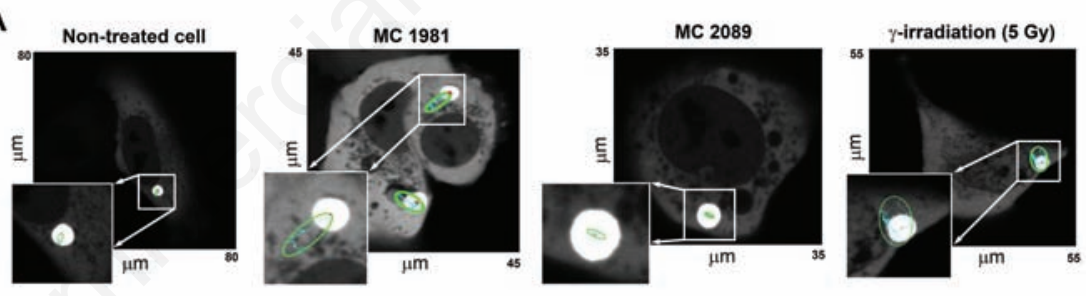

B

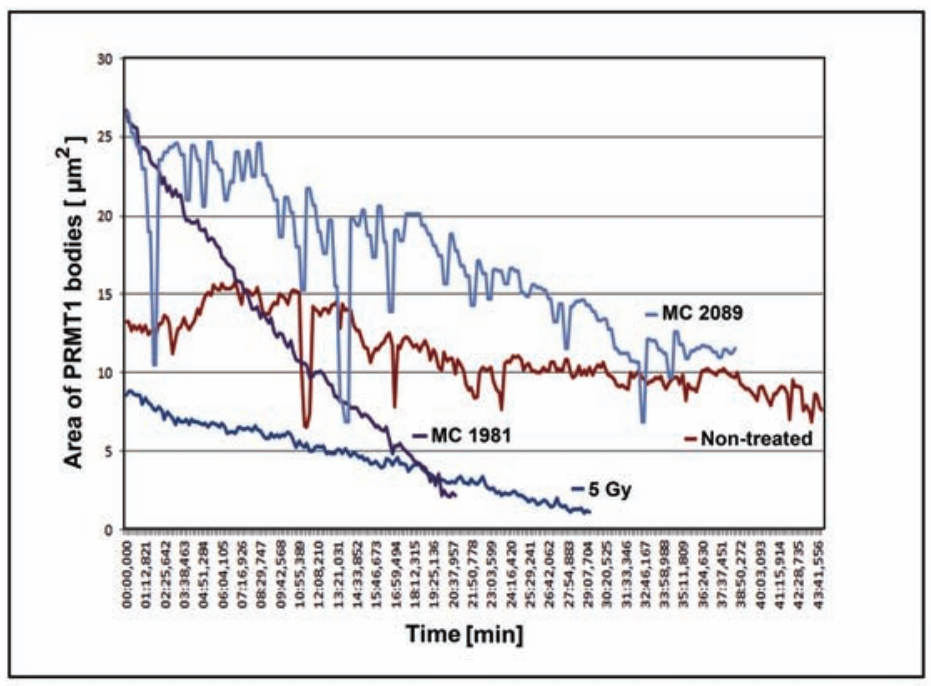

Figure 5. Single particle tracking analysis of PRMT1 nuclear bodies. A) Localized movement of PRMT1 nuclear bodies was analyzed in non-treated control cells, after treatment by MC 1981, MC 2089 and irradiation by 5 Gy of $\gamma$-rays; enclosed ellipses around tracks (blue) of individual nuclear bodies are shown. B) Time-dependent area of PRMT1 nuclear bodies in $\mu^{2}$ in non-treated control cells, after treatment by MC 1981, MC 2089 and irradiation by 5 Gy of $Y$-rays. 
could be a cytoplasmic reservoir of PRMT1 that methylates histones at arginine residues directly in cytoplasm, as was shown for lysine methyltransferases. ${ }^{43}$ To test these options, cells transiently expressing YFP-PRMT1 were treated with the proteasome inhibitor MG 132. Pronounced changes were observed in U20S and HeLa cell morphologies after 16 hours of treatment. The results showed that only $5 \%$ of the treated and transfected cells had one PRMT1 cytoplasmic body (Figure 6A, arrow), and $95 \%$ of the cells were devoid of of this structure and morphology of the cells was pronouncedly changed (see Figure 6A in comparison with control cell in Figure 1Ab).

\section{PRMT1 kinetics in response to UV- A light or $\gamma$-irradiation}

We microirradiated U20S cell nuclei with a UV-A laser (wavelength $355 \mathrm{~nm}$ ) to induce DNA damage and performed time-lapse confocal microscopy to monitor kinetics of PRMT1 cytoplasmic bodies (Figure 6B). After local microirradiation of cell nuclei with UV-A light, the PRMT1 cytoplasmic bodies begins to disappear within $10 \mathrm{~s}$, and complete disappearance occurred within approximately 3 to $35 \mathrm{~min}$, depending on the size of the original PRMT1 cytoplasmic body (Figure 6B, graph). The same effect occurred in response to irradiation with 5 Gy of $\gamma$-rays, leading to the disappearance of PRMT1 cytoplasmic bodies within 30 to $35 \mathrm{~min}$ (Figures 5B and 6C). We also analyzed simultaneous responses of endogenous and exogenous PRMT1 to $\gamma$-irradiation and in comparison with non-treated control cells, we confirmed that $\gamma$-rays caused disassembly of PRMT1 cytoplasmic bodies (Figure 6D, arrows). Since PRMT1 is involved in DNA repair, we hypothesized that it could accumulate in DNA-damage foci after gamma irradiation, or in UV-A irradiated nuclear regions, similar to that for the other DDR-related proteins $^{26,44,45}$ (Supplementary Figure 1B). However, we did not find any evidence for PRMT1 accumulation at locally induced DNA lesions in U2OS cell nuclei or in HeLa cells (Figure 6B, irradiated ROI).

As, we found that ionizing radiation and PRMT1 inhibitors induce the disassembly of PRMT1 cytoplasmic bodies, DNA damage potential of these treatments should be also taken into account. Thus, we tested the pattern of 53BP1 nuclear bodies. We analyzed the nuclear localization pattern of 53BP1 in untreated control U20S cells, $\gamma$-irradiated U20S cells, and U20S cells treated with the PRMT1 inhibitors MC 1981 and MC 2089. We found that MC 1981 abolished the formation of spontaneous 53BP1 nuclear bodies (NBs), even in combination with $\gamma$-radiation (Figure 7B). Interestingly, in control cells, 53BP1-positive NBs appeared in both untransfected cells
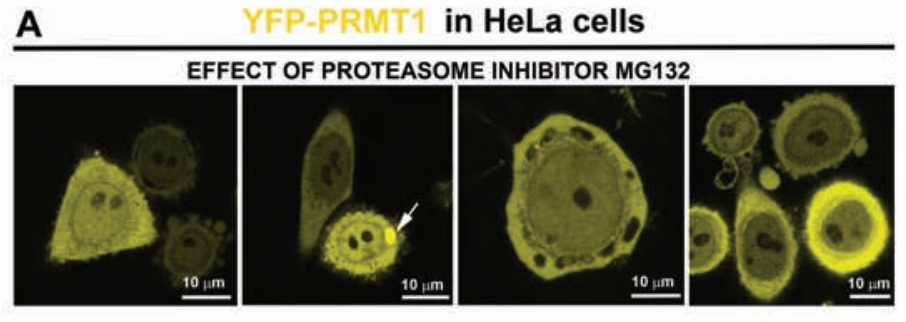

B YFP-PRIMT1 in U2OS cells

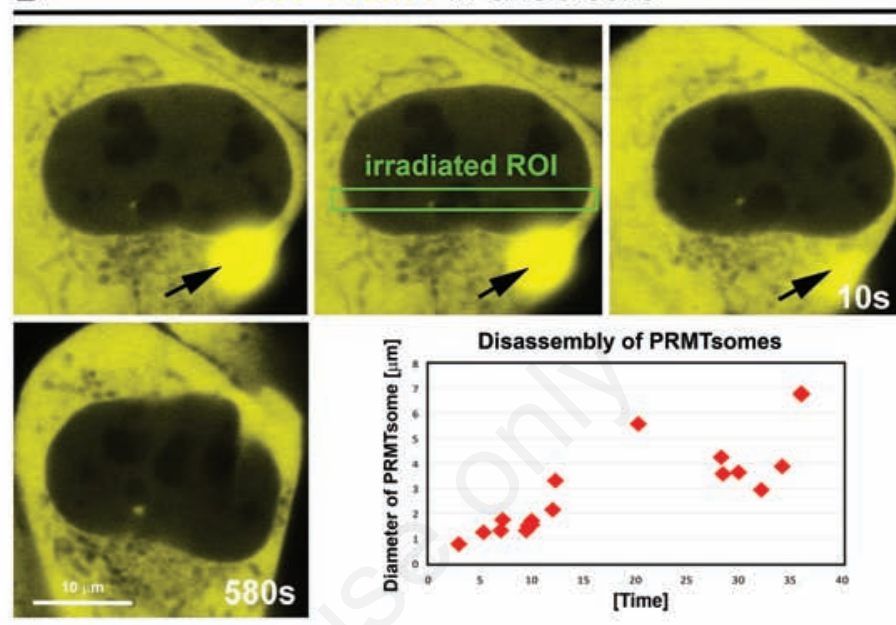

C YFP-PRIMT1 in U2OS cells / $\gamma$-irradiation [5 Gy]
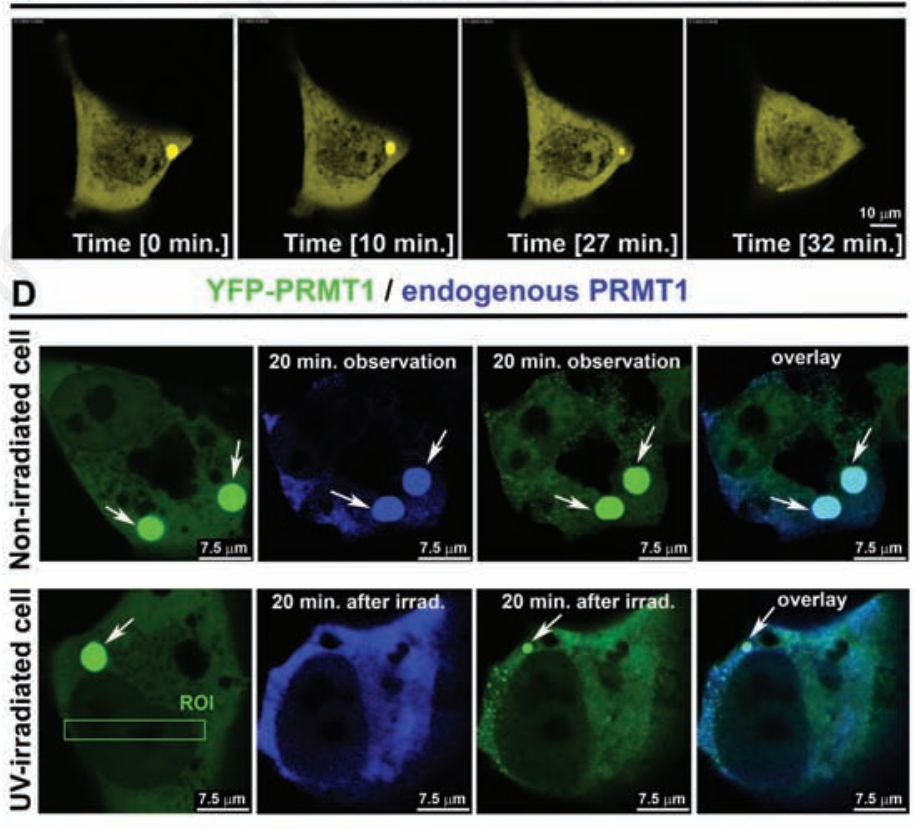

Figure 6. PRMT1 cytoplasmic bodies morphology in U2OS cells after treatment with proteasome inhibitor, UV-A, and Y-radiation. A) Effect of proteosome inhibitor MG 132 on PRMT1 localization and morphology of PRMT1 cytoplasmic bodies (arrow). B) Nuclei were microirradiated with UV-A light (wavelength $355 \mathrm{~nm}$ ); the irradiated region was within the green frame (region of interest - ROI); PRMT1 cytoplasmic bodies rapidly disassembled after UV-A irradiation; disassembly was dependent on the size of PRMT1 cytoplasmic bodies (graph). PRMT1 recruitment to locally induced DNA lesions (to ROIs) was not observed at $580 s$ after UV-A irradiation. C) Time-lapse microscopy shows the disappearance of PRMT1 cytoplasmic bodies within $32 \mathrm{~min}$ after Y-irradiation. D) PRMT1 bodies were visualized by YFP (green) and by appropriate antibody (blue); size of PRMT1 bodies was reduced $20 \mathrm{~min}$ after UV-A irradiation, while in control non-irradiated cells, stable morphology of PRMT-1 cytoplasmic bodies was found. 
and in cells overexpressing PRMT1 (Figure $7 \mathrm{~A})$. The other compound, MC 2089, did not change the morphology of spontaneous 53BP1 NBs in comparison with control cells (Figure 7A). Combination of MC 2089 and $\gamma$-radiation did not affect formation of 53BP1-positive IRIF as observed after cell exposure to 5 Gy of $\gamma$-rays (Figure 7B). Interestingly the nuclear pattern of $\gamma \mathrm{H} 2 \mathrm{AX}$ was identical in control and MC 1981 treated cells or when we compared $\gamma$-irradiated cells with combination of $\gamma$-irradiation and MC 1981 or $\gamma$-irradiation and MC 2089 treatment (Figure 7C).

Dynamics of PRMT1 in the nucleus and cytoplasm measured by FRAP

We performed FRAP (Fluorescence Recovery after Photobleaching) analysis for YFPPRMT1v1 in the nucleoplasm, cytoplasm, and PRMT1 cytoplasmic bodies (Figure 8 A-D), and tested the effects of PRMT1 inhibitors on PRMT1 dynamics. We observed that the fluorescence of PRMT1 in the PRMT1 cytoplasmic bodies recovered more rapidly than that in the nucleoplasm or the cytoplasm in untreated U20S and HeLa cells (Figure 8 A,B). These results showed that PRMT1 in PRMT1 cytoplasmic bodies is not bound to stable structures, and is probably present in a lower oligomeric state than nuclear or cytoplasmic PRMT1. The PRMT1 dynamics in U20S cells treated with MC 1981 and MC 2089 were not significantly different than those in untreated control cells (Figure $8 \mathrm{~A}, \mathrm{C}, \mathrm{D})$. These results indicate that PRMT1 inhibitors have no effect on the diffusion of PRMT1 (Figure 8), but significantly affect the localized movement of PRMT1 cytoplasmic bodies, especially MC 1981 (Figures 4 and $5 \mathrm{~B})$.

\section{Levels of PRMT1 after selected} treatments and morphology of PRMT1 bodies in relationship to cytoskeleton and mitochondria

Here, we additionally tested an effect of PRMT1 inhibitors and $\gamma$-radiation on total levels of PRMT1 variants (Figure 9A). We observed that endogenous PRMT1 variants are reduced after $48 \mathrm{~h}$ of MC 1981 and MC 2089 treatment and after $24 \mathrm{~h}$ of MC 2089 treatment of U20S cells. Level of exogenous PRMT1 (YFP-PRMT1-v1) was reduced $48 \mathrm{~h}$ after MC 1981 and MC 2089 exposure, but $\gamma$-irradiation increased the total level of YFP-PRMT1, which supports our conclusion on importance of PRMT1 function in DNA damage response (Figure 9A). We also analyzed cytoskeletal proteins and the $26 \mathrm{~S}$ proteasome and link these structures to PRMT1 bodies. We found that there is a low level of $26 \mathrm{~S}$ proteasome in the cyctoplasmic region where PRMT1 body is located (Figure 9B, arrows). Microtubules are

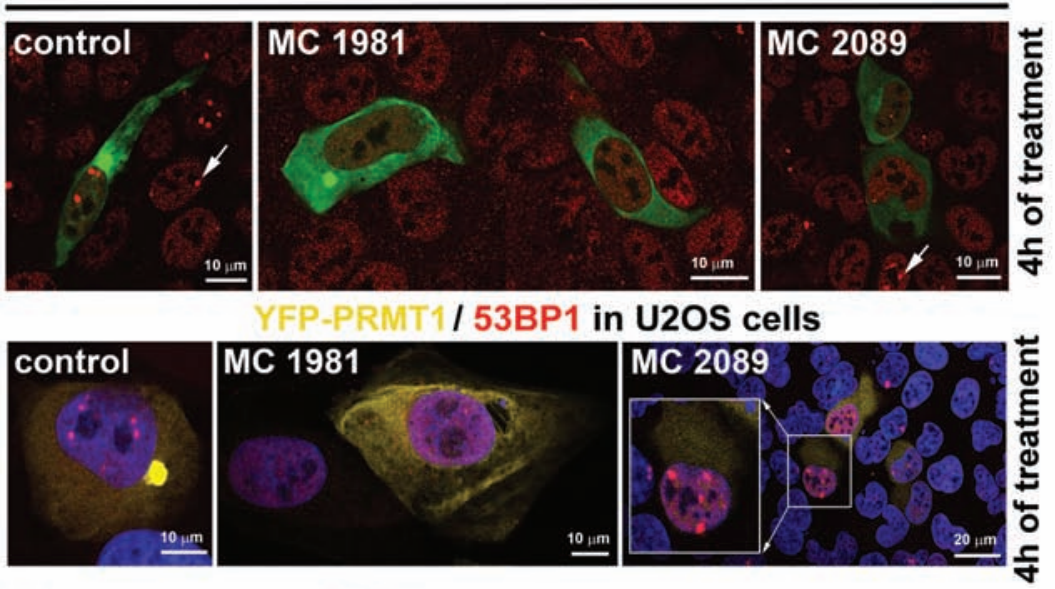

B

53BP1 in U2OS cells

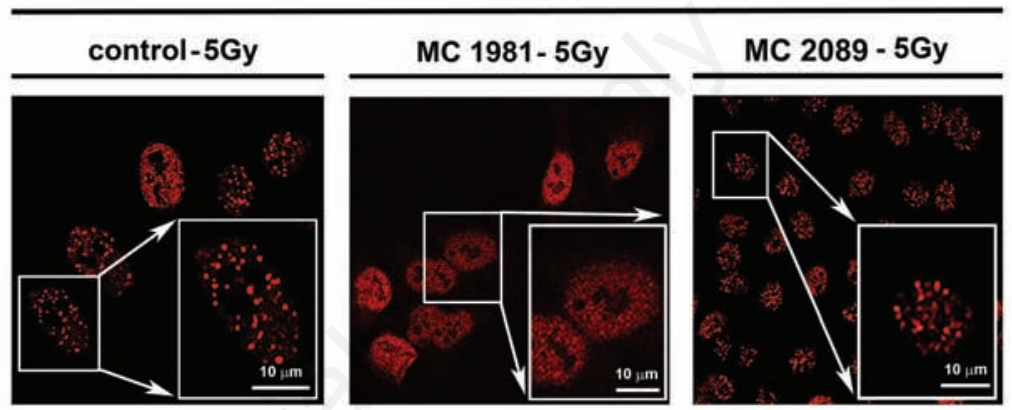

C

$\gamma \mathrm{H} 2 \mathrm{AX}$ in U2OS cells

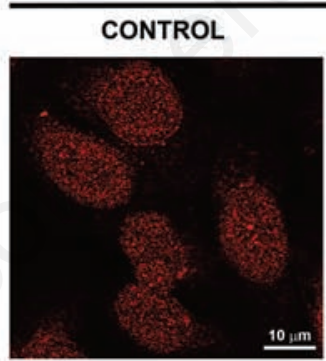

5 Gy
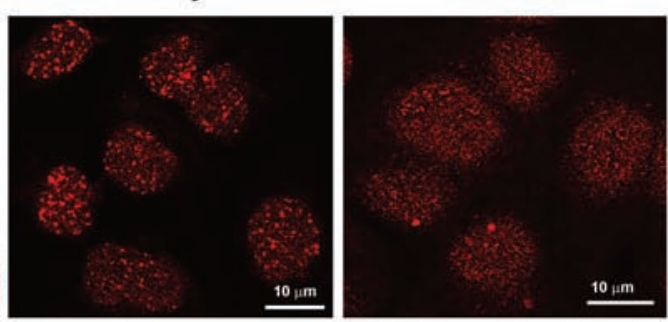

MC 2089

MC 1981-5Gy
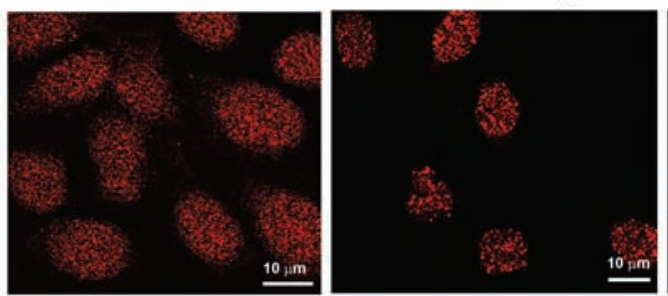

MC 2089 - 5Gy

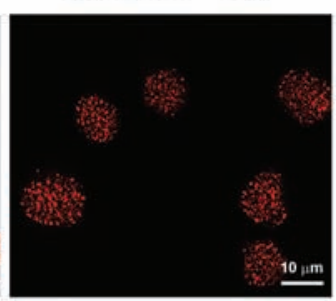

Figure 7. 53BP1 localization in U2OS cells treated with MC 1981 and MC 2089. A) 53BP1 localization in untreated control U2OS cells (left), in cells treated with MC 1981 (middle), and in cells treated with MC 2089 (right); results of two independent experiments are shown. B) Morphology of 53BP1 nuclear bodies (red) in Y-irradiated cells and after combined treatment by $\gamma$-irradiation and MC 1981 or $\gamma$-irradiation and MC 2089. C) Nuclear pattern of $\gamma \mathrm{H} 2 \mathrm{AX}$ in non-treated control cells, cells exposed to $\gamma$-rays (5Gy) or MC 1981, MC 2089 inhibitors; U2OS cells were also exposed to combination of $\gamma$ irradiation and MC 1981 inhibitor or $\gamma$-irradiation and MC 2089 inhibitor. 
intertwined around PRMT1 bodies (Figure 9C) and PRMT1-positive nuclear bodies were in a mutual contact with mitochondria, but PRMT1 nuclear bodies did not directly co-localized with mitochondria (Figure 9D). Interestingly, F-actin level was reduced after 4 and $48 \mathrm{~h}$ of MC 2089 treatment and MC 1981 caused accummulation of autofluorescent structures closer to the cell nucleus $48 \mathrm{~h}$ after the treatment (Figure 10A, arrows). Similarly as $\alpha$ tubulin (Figure 9C), F-actin was intertwined around PRMT1 bodies (Figure 10B). Moreover, morphology of $\alpha$-tubulin was changed after MC 1981 cell treatment, but not after cell exposure to MC 2089 (Figure 10C).

\section{Discussion}

This paper showed that PRMT1 can accumulate in a large structure (designated as PRMT1 cytoplasmic bodies) in the cytoplasm of human and mouse cells. Cells typically contained one PRMT1 cytoplasmic body. These bodies were often observed close to the cell nucleus and they were detected in transiently transfected cells (Figures 1 to 5). We first assumed that PRMT1 cytoplasmic bodies appear due to the aggregation of overexpressed protein. However, further examination showed that similar structures, containing endogenous PRMT1, exist in untransfected control cells studied by immunofluorescence (Figure 1C ce). Moreover, the expressed YFP-PRMT1 in the PRMT1 cytoplasmic bodies was dynamically exchanged with the cytoplasmic and the nuclear pools of PRMT1, and had higher mobility. For example, we found that the kinetics of PRMT1 cytoplasmic bodies was modulated by specific PRMT1 inhibitors and by radiation (Figures 4, 5 and 6 B,C). PRMT1 cytoplasmic bodies disappeared after the treatments and then recovered, which indicated that they were bona fide components of normal cells and were not caused by other process such as apoptosis. Here, we also tested if PRMT1 bodies can be considered as components of structures called aggresomes. ${ }^{46}$ Aggresomes are cellular structures consisting of misfolded cytoplasmic proteins as well as dislocated variants of transmembrane proteins. ${ }^{47}$ These aggregates are characterized by deposits of proteinaceous material, ubiquitin and proteasome subunits around the microtubule organizing centers. Thus, we have analyzed a morphological link between PRMT1 cytoplasmic bodies and 26S proteasome, mitochondria and proteins of cytoskeleton (Figures 9 and 10). Because cytoskeletal components, $\alpha$-tubulin and Factin, intertwined around PRMT1 bodies, these results imply that PRMT1 bodies could be components of aggressomes (compare
Figure 1C d, with aggresome morphology in Figure 3 published by Kopito and Sitia ${ }^{46}$ ). Here, we additionally observed PRMT1 bodies located in cytoplasmic regions with a reduced level of $26 \mathrm{~S}$ proteasome (Figure 9B, arrows). These results did not exclude PRMT1 bodies as components of aggresome, because PRMT1 bodies likely force out $26 \mathrm{~S}$ proteasome.

In our study, we additionally observed that PRMT1 cytoplasmic bodies respond to the injury by irradiation. Locally induced DNA damage in the cell nucleus by UV-A laser induced immediate dissociation of the PRMT1 bodies in the cytoplasm (Figure 6B). Thus, we hypothesized that PRMT1 might be recruited to damaged sites and depleted from PRMT1 cytoplasmic bodies. However, there was no evidence for specific accumulation of PRMT1 in UV-A induced double strand breaks (see ROI in Figure 6B). Our work and experiments of other authors previously showed such increased levels for other epigenetically important proteins, including phosphorylation of histone H2AX, heterochromatin protein 1 (HP1), or Polycombgroup (PcG) proteins ${ }^{25,29,44,45,48,49}$ (Supplementary Figure 1B). However, our results document that PRMT1 did not pronouncedly accumulate to DNA lesions, but PRMT1 cytoplasmic bodies responded very rapidly to DNA damage (Figure 6B). This result
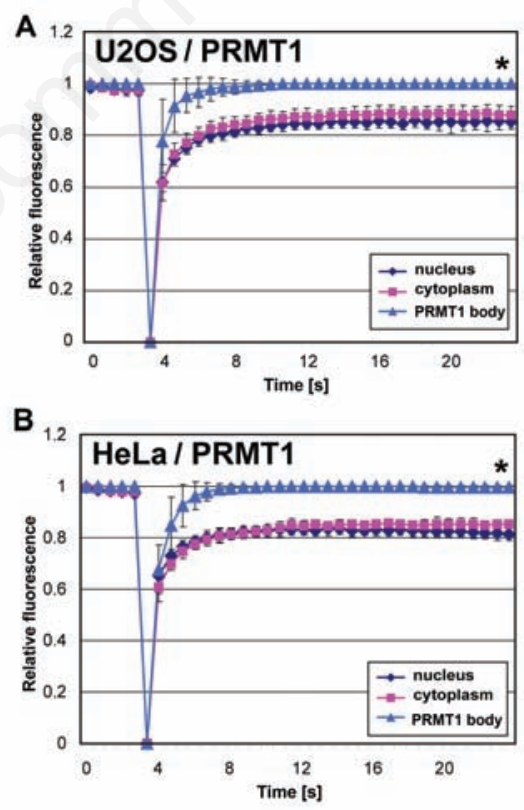

Figure 8. FRAP analysis of PRMT1 kinetics in nucleus, cytoplasm, and PRMT1 cytoplasmic bodies. A) PRMT1 dynamics in untreated control U2OS cells. B) PRMT1 dynamics in untreated control HeLa cells. C) PRMT1 dynamics in U2OS cells treated with MC 1981 for $4 \mathrm{~h}$. D) PRMT1 dynamics in U2OS cells treated with MC 2089 for 1-2 h. Asterisks mark statistically significant differences from values measured for PRMT1 dispersed in the cytoplasm $(P \leq 0.05)$. Statistical analyses were performed using Student's t-test on data normalized to 1 ; results are given as mean \pm SEM.
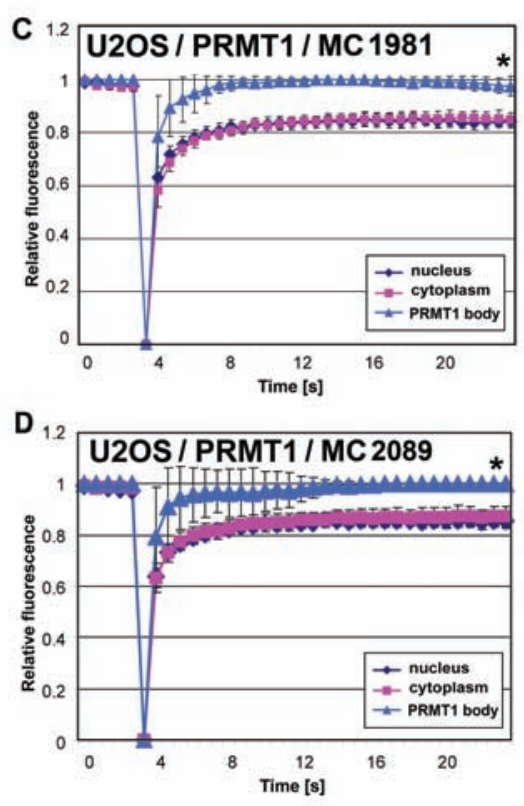

was consistent with data reported by Boisvert et al., ${ }^{22}$ who showed that MRE11 (a component of the MRN complex involved in homologous recombination DNA repair) was methylated by PRMT1 in a C-terminal glycine-arginine rich domain. Thus, PRMT1 must be unambiguously involved in DDR. The same authors showed cells treated with methylase inhibitors NBs to the sites of DNA damage. Here, we additionally found that treatment by PRMT1 inhibitor, MC 1981, or combination of MC 1981 treatment with $\gamma$-irradiation prevents formation of 53BP1-positive foci that are markers of DNA lesions (Figure $7 \mathrm{~A}, \mathrm{~B}$ ). This observation important from the view of knowledge on 53BP1 methylation by PRMT1, which essential for DNA repair in somatic cells. ${ }^{50}$

PRMT1 cytoplasmic bodies are not passive aggregates, and suggested that these stuctures may provide a useful experimental model to study PRMT1 inhibitors or PRMT1 function in repair signaling pathways. We showed en ic events, especially those involved in the response to DNA damage. Specific enzyme inhibitors can give detailed insight into biological pathways. Therefore, we tested the effect 

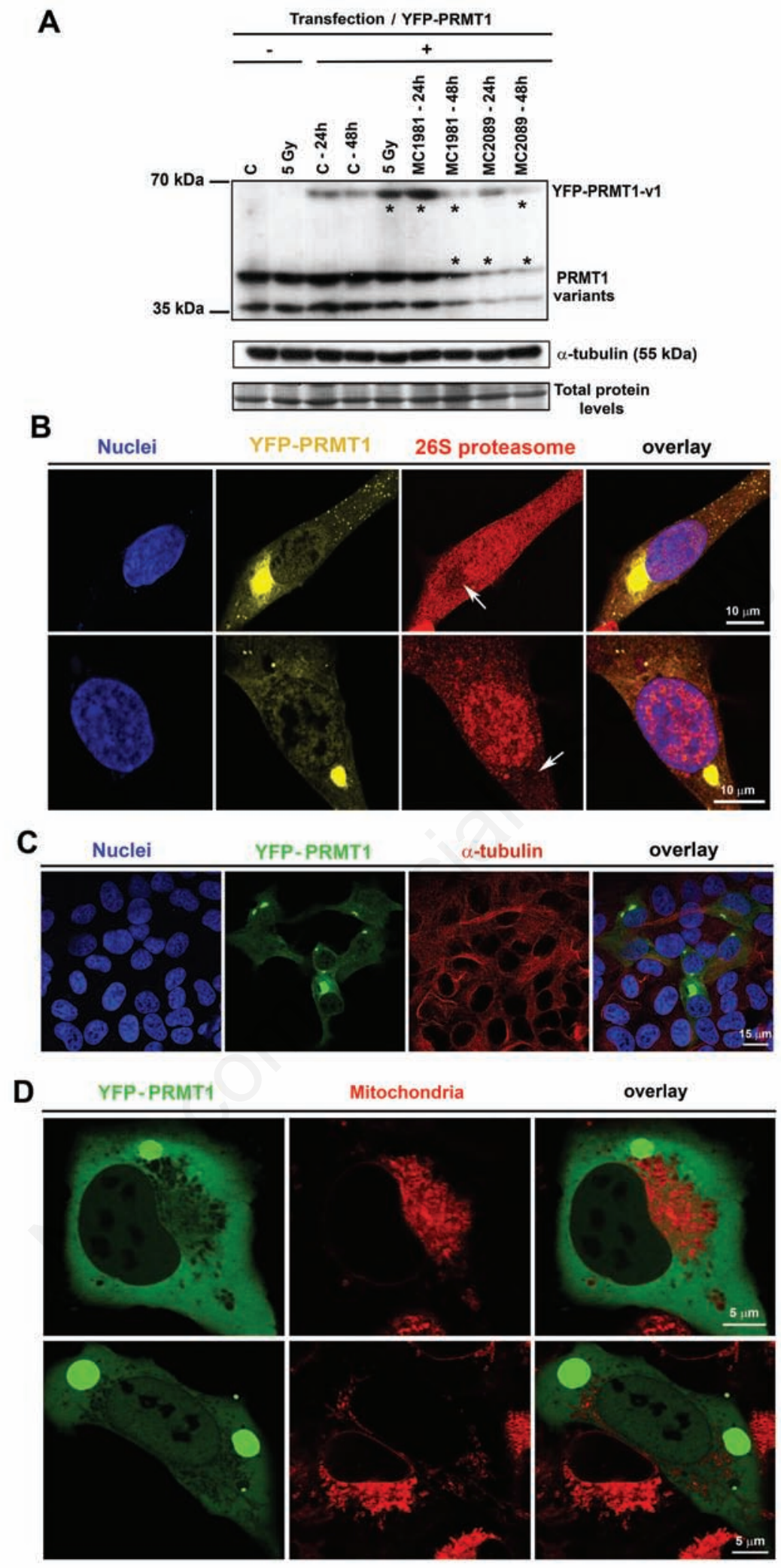

Figure 9. Western blot analyses showing the levels of PRMT1 after selected treatments and cell morphology. A) Western blots on PRMT1 levels in non-treated control U2OS cells and Y-irradiated cells; Western blot analyses were also performed in U2OS cells transfected by plasmid DNA encoded YFP-PRMT1 in non-treated control U2OS cells, $\gamma$-irradiated cells and the cells treated with MC 1981 and MC 2089 for 24 and $48 \mathrm{~h}$; data from western blots were normalized to the $\alpha$-tubulin and total protein levels. B) Immunofluorescent analyses of $26 \mathrm{~S}$ proteasome (red) and morphology of YFP-PRMT1 (yellow); cell nuclei were visualized by DAPI (blue). C) Immunofluorescent analyses of $\alpha$-tubulin (red) in relationship to YFP-PRMT1 bodies (green) in non-treated control U2OS cells. D) Morphology of mitochondria (red) and YFP-PRMT1 positive cytoplasmic bodies (green) analyzed in non-treated control cells. 
A

F-actin / Nuclei / U2OS cells
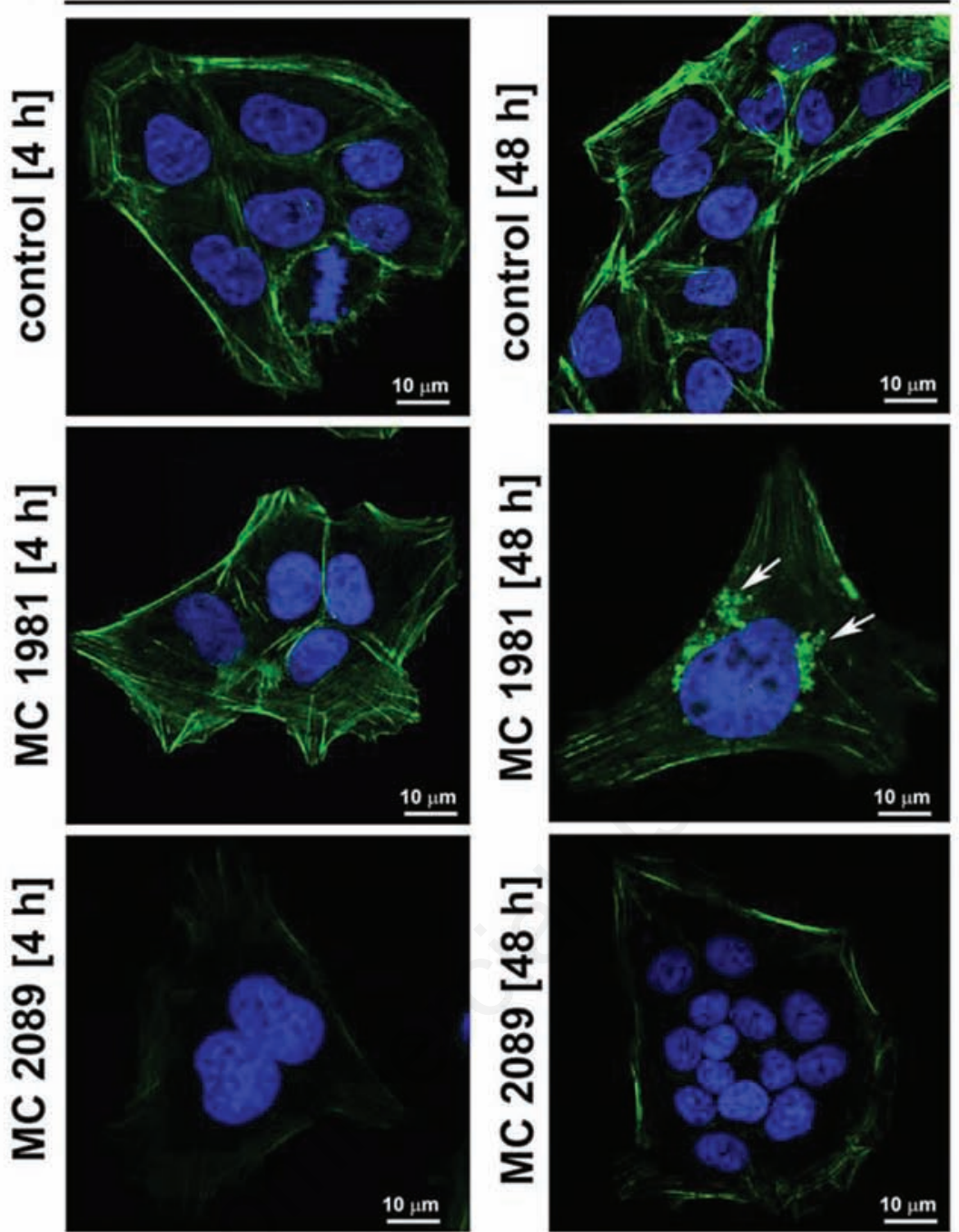

B

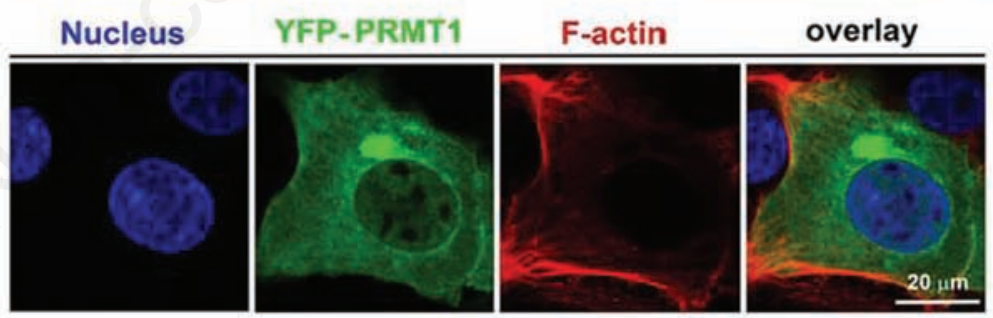

C $\alpha$-tubulin / DAPI /U2OS cells [48 h]

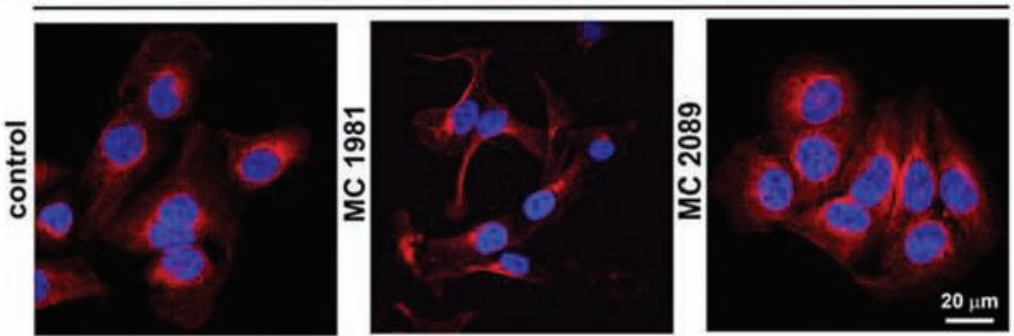

Figure 10. Morphology of F-actin filaments after PRMT1 inhibitory treatment. A) F-actin (green) was visualized by FITC-conjugated phalloidin (green) in control non-treated U2OS cells and 4 or $48 \mathrm{~h}$ of MC 1981 and MC 2089 treatment.(B) Spatial relationship between YFP-PRMT1 bodies (green) and F-actin filaments (red). C) Morphology of $\alpha$-tubulin (red) in non-treated and MC 1981 or MC 2089 treated cells; cell nuclei were stained by DAPI (blue). 
of two PRMT1 inhibitors on PRMT1 cytoplasmic body localized movement in live cells, and interestingly, there was a difference in the time-course of inhibitor effects. Both MC 1981 and MC 2089 clearly affected PRMT1 cytoplasmic body movement and led to their disappearance (Figures 3B and 4B). Cells recovered after treatment with MC 2089 for $48 \mathrm{~h}$, and PRMT1 cytoplasmic bodies were regenerated (Figure 4C). MC 1981 had a stronger effect on the epigenome and caused downregulation of YFP-PRMT1 after $48 \mathrm{~h}$ of treatment (Figure $3 \mathrm{~B})$. It is well known that epi-drugs can have pleotropic effects and biological limitations. Therefore, a fundamental knowledge of the epigenome status before and after drug treatment (or after combinatory treatment by epidrugs and irradiation) should contribute to the general knowledge on DDR. Important steps to this knowledge are not only genomewide analyses, but also single-cell analyses of the epigenome in living cellular systems.

\section{References}

1. Kouzarides T. Chromatin modifications and their function. Cell 2007;128:693-705.

2. Fackelmayer FO. Protein arginine methyltransferases: guardians of the Arg? Trends Biochem Sci 2005;30:666-71.

3. Pal S, Sif S. Interplay between chromatin remodelers and protein arginine methyltransferases. J Cell Physiol 2007;213:30615.

4. Majumder S, Alinari L, Roy S, Miller T, Datta J, Sif S, et al. Methylation of histone $\mathrm{H} 3$ and $\mathrm{H} 4$ by PRMT5 regulates ribosomal RNA gene transcription. J Cell Biochem 2010;109:5535-63.

5. Boisvert FM, Ahmad Y, Gierliński M, Charrière F, Lamont $\mathrm{D}$, Scott $\mathrm{M}$, et al. A quantitative spatial proteomics analysis of proteome turnover in human cells. Mol Cell Proteomics 2012;11: M111.011429.

6. Yu MC, Bachand F, McBride AE, Komili S, Casolari JM, Silver PA. Arginine methyltransferase affects interactions and recruitment of mRNA processing and export factors. Genes Dev 2004;18:202435.

7. Yun CY, Fu XD. Conserved SR protein kinase functions in nuclear import and its action is counteracted by arginine methylation in Saccharomyces cerevisiae. J Cell Biol 2000;150:707-718.

8. Herrmann F, Pably P, Eckerich C, Bedford MT, Fackelmayer FO. Human protein arginine methyltransferases in vivo - distinct properties of eight canonical members of the PRMT family. J Cell Sci 2009;122:66777.
9. Bedford MT, Richard S. Arginine methylation an emerging regulator of protein function. Mol Cell 2005;18:263-72.

10. Pal S, Yun R, Datta A, Lacomis L, Erdjument-Bromage $\mathrm{H}$, Kumar $\mathrm{J}$, et al. $\mathrm{mSin} 3 \mathrm{~A} /$ histone deacetylase 2- and PRMT5-containing Brg1 complex is involved in transcriptional repression of the Myc target gene cad. Mol Cell Biol 2003;23:7475-87.

11. Pal S, Vishwanath SN, ErdjumentBromage H, Tempst P, Sif S. Human SWI/SNFassociated PRMT5 methylates histone $\mathrm{H} 3$ arginine 8 and negatively regulates expression of ST7 and NM23 tumor suppressor genes. Mol Cell Biol 2004;24:9630-45.

12. Fodor BD, Kubicek S, Yonezawa M, 0'Sullivan RJ, Sengupta R, Perez-Burgos $\mathrm{L}$, et al. Jmjd2b antagonizes H3K9 trimethylation at pericentric heterochromatin in mammalian cells. Genes Dev 2006;20:1557-62.

13. Harničarová Horáková A, Galiová G, Legartová S, Kozubek S, Matula P, Bártová E. Chromocentre integrity and epigenetic marks. J Struct Biol 2010;169:124-33.

14. El-Andaloussi N, Valovka T, Toueille M, Hassa P0, Gehrig P, Covic M, et al. Methylation of DNA polymerase $\beta$ by protein arginine methyltransferase 1 regulates its binding to proliferating cell nuclear antigen. FASEB J 2007;21:26-34.

15. El-Andaloussi N, Valovka T, Toueille M, Steinacher R, Focke F, Gehrig $\mathrm{P}$, et al. Arginine methylation regulates DNA polymerase beta. Mol Cell 2006;22:51-62.

16. Umar A, Buermeyer AB, Simon JA, Thomas DC, Clark AB, Liskay RM, et al. Requirement for PCNA in DNA mismatch repair at a step preceding DNA resynthesis. Cell 1996;87:65-73.

17. Essers J, Theil AF, Baldeyron C, van Cappellen WA, Houtsmuller AB, Kanaar R, et al. Nuclear dynamics of PCNA in DNA replication and repair. Mol Cell Biol 2005;25:9350-9.

18. Jackson SP, Bartek J. The DNA-damage response in human biology and disease. Nature 2009;461:1071-1078.

19. Hartlerode AJ, Scully R. Mechanisms of double-strand break repair in somatic mammalian cells. Biochem J 2009;423:157-68.

20. Pardo B, Gómez-González B, Aguilera A. DNA repair in mammalian cells: DNA double-strand break repair: how to fix a broken relationship. Cell Mol Life Sci 2009;66:1039-56.

21. Soria G, Polo SE, Almouzni G. Prime, repair, restore: the active role of chromatin in the DNA damage response. Mol Cell 2012;46:722-34.
22. Boisvert FM, Hendzel MJ, Masson JY, Richard S. Methylation of MRE11 regulates its nuclear compartmentalization. Cell Cycle 2005;4:981-9.

23. Rogakou EP, Pilch DR, Orr AH, Ivanova VS, Bonner WM. DNA double-stranded breaks induce histone $\mathrm{H} 2 \mathrm{AX}$ phosphorylation on serine 139. J Biol Chem 1998;273:5858-68.

24. Polo SE, Jackson SP. Dynamics of DNA damage response proteins at DNA breaks: a focus on protein modifications. Genes Dev 2011;25:409-33.

25. Bártová E, Šustáčková G, Stixová L, Kozubek S, Legartová S, Foltánková V. Recruitment of 0ct4 protein to UV-damaged chromatin in embryonic stem cells. PLoS ONE 2011;6:e27281.

26. Šustáčková G, Kozubek S, Stixová L, Legartová S, Matula $\mathrm{P}$, Orlova $\mathrm{D}$, et al. Acetylation-dependent nuclear arrangement and recruitment of BMI1 protein to UV-damaged chromatin. J Cell Physiol 2012;227:1838-50.

27. Galanty Y, Belotserkovskaya R, Coates J, Jackson SP. RNF4, a SUMO-targeted ubiquitin E3 ligase, promotes DNA doublestrand break repair. Genes Dev 2012;26:1179-95.

28. Hakmé A, Huber A, Dollé P, Schreiber V. The macroPARP genes Parp-9 and Parp-14 are developmentally and differentially regulated in mouse tissues. Dev Dyn 2008;237:209-215.

29. Chou DM, Adamson B, Dephoure NE, Tan $X$, Nottke AC, Hurov KE, et al. A chromatin localization screen reveals poly (ADP ribose)-regulated recruitment of the repressive polycomb and NuRD complexes to sites of DNA damage. Proc Natl Acad Sci USA 2010;107:18475-80.

30. Ragno R, Simeoni S, Castellano S, Vicidomini C, Mai A, Caroli A, et al. Small molecule inhibitors of histone arginine methyltransferases: homology modeling, molecular docking, binding mode analysis, and biological evaluations. J Med Chem 2007;50:1241-53.

31. Castellano S, Milite C, Ragno R, Simeoni $\mathrm{S}$, Mai A, Limongelli V, et al. Design, synthesis and biological evaluation of carboxy analogues of arginine methyltransferase inhibitor 1 (AMI-1). ChemMedChem 2010;5:398-414.

32. Martinet N, Bertrand P. Interpreting clinical assays for histone deacetylase inhibitors. Cancer Manag Res 2011;3:117141.

33. Šustáčková G, Legartová S, Kozubek S, Stixová L, Pacherník J, Bártová E. Differentiation-independent fluctuation of pluripotency-related transcription factors and other epigenetic markers in embryonic stem cell colonies. Stem Cells Dev 
2012;21:710-20.

34. Bártová E, Krejčí J, Harničarová A, Kozubek S. Differentiation of human embryonic stem cells induces condensation of chromosome territories and formation of heterochromatin protein 1 foci. Differentiation 2008;76:24-32.

35. Herrmann F, Lee J, Bedford MT, Fackelmayer FO. Dynamics of human protein arginine methyltransferase 1(PRMT1) in vivo. $\mathrm{J}$ Biol Chem 2005;280:38005-10.

36. Orlova DY, Stixová L, Kozubek S, Gierman HJ, Šustáčková G, Chernyshev AV, et al. Arrangement of nuclear structures is not transmitted through mitosis but is identical in sister cells. J Cell Biochem 2012;113:3313-29.

37. Strašák L, Bártová E, Harničarová A, Galiová G, Krejčí J, Kozubek S. H3K9 acetylation and radial chromatin positioning. J Cell Physiol 2009;220:91-101.

38. Mai A, Cheng D, Bedford MT, Valente S, Nebbioso A, Perrone A, et al. Epigenetic multiple ligands: mixed histone/protein methyltransferase, acetyltransferase, and class III deacetylase (sirtuin) inhibitors. J Med Chem 2008;51:2279-90.

39. Goulet I, Gauvin G, Boisvenue S, Côté J.
Alternative splicing yields protein arginine methyltransferase 1 isoforms with distinct activity, substrate specificity, and subcellular localization. J Biol Chem 2007;282:33009-21.

40. Stixová L, Matula P, Kozubek S, Gombitová A, Cmarko D, Raška I, Bártová. Trajectories and nuclear arrangement of PML bodies are influenced by A-type lamin deficiency. Biol Cell 2012;104:418-32.

41. Ciechanover A. Intracellular protein degradation: from a vague idea thru the lysosome and the ubiquitin-proteasome system and onto human diseases and drug targeting. Exp Biol Med (Maywood) 2006;231:1197-211.

42. Su HL, Li SS. Molecular features of human ubiquitin-like SUMO genes and their encoded proteins. Gene 2002;296:65-73.

43. Pinheiro I, Margueron R, Shukeir N, Eisold M, Fritzsch C, Richter FM et al. Prdm3 and Prdm16 are H3K9me1 methyltransferases required for mammalian heterochromatin integrity. Cell 2011;150:948-60.

44. Ayoub N, Jeyasekharan AD, Bernal JA, Venkitaraman AR. HP1- $\beta$ mobilization promotes chromatin changes that initiate the DNA damage response. Nature 2008;453:682-6.
45. Luijsterburg MS, Dinant C, Lans H, Stap J, Wiernasz E, Lagerwerf $\mathrm{S}$, et al. Heterochromatin protein 1 is recruited to various types of DNA damage. J Cell Biol 2009;185:577-86.

46. Kopito RR, Sitia R. Aggresomes and Russell bodies. Symptoms of cellular indigestion? EMBO Rep 2000;1:225-31.

47. García-Mata R, Bebök Z, Sorscher EJ, Sztul ES. Characterization and dynamics of aggresome formation by a cytosolic GFPchimera. J Cell Biol 1999;146:1239-54.

48. Ismail IH, Andrin C, McDonald D, Hendzel MJ. BMI1-mediated histone ubiquitylation promotes DNA double-strand break repair. J Cell Biol 2010;191:45-60.

49. Gieni RS, Ismail IH, Campbell S, Hendzel MJ. Polycomb group proteins in the DNA damage response: a link between radiation resistance and "stemness". Cell Cycle 2011;10:883-94.

50. Boisvert FM, Rhie A, Richard S, Doherty AJ. The GAR motif of 53BP1 is arginine methylated by PRMT1 and is necessary for 53BP1 DNA binding activity. Cell Cycle 2005;4:1834-41. 